\title{
Salt generates antiinflammatory Th17 cells but amplifies pathogenicity in proinflammatory cytokine microenvironments
}

\author{
Julia Matthias, ${ }^{1,2,3}$ Sylvia Heink, ${ }^{4,5}$ Felix Picard, ${ }^{6}$ Julia Zeiträg, ${ }^{7}$ Anna Kolz, ${ }^{8}$ Ying-Yin Chao, ${ }^{1,2,9}$ Dominik Soll,, ${ }^{1,2}$ \\ Gustavo P. de Almeida, ${ }^{1,2,9}$ Elke Glasmacher, ${ }^{10}$ Ilse D. Jacobsen, ${ }^{11,12}$ Thomas Riedel, ${ }^{13}$ Anneli Peters, ${ }^{8}$ Stefan Floess, ${ }^{14}$ \\ Jochen Huehn, ${ }^{14}$ Dirk Baumjohann, ${ }^{7}$ Magdalena Huber, ${ }^{6}$ Thomas Korn, ${ }^{4,5}$ and Christina E. Zielinski ${ }^{1,2,3,9}$
}

\begin{abstract}
IInstitute of Virology, Technical University of Munich, Munich, Germany. ${ }^{2}$ Cerman Center for Infection Research, Partner Site Munich, Munich, Germany. ${ }^{3}$ Department of Cellular Immunoregulation, Charité - Universitätsmedizin Berlin, Berlin, Germany. ${ }^{4}$ Klinikum rechts der Isar, Department of Experimental Neuroimmunology, Technical University of Munich, Munich, Germany. ${ }^{5}$ Munich Cluster for Systems Neurology (SyNergy), Munich, Germany. ${ }^{6}$ Institute for Medical Microbiology and Hygiene, University of Marburg, Marburg, Germany. ${ }^{7}$ Institute for Immunology, Biomedical Center, Faculty of Medicine, Ludwig Maximilian University of Munich (LMU Munich), Planegg-Martinsried, Germany. ${ }^{8}$ Institute of Clinical Neuroimmunology, Hospital and Biomedical Center of LMU Munich, Planegg-Martinsried, Germany. ${ }^{9}$ TranslaTUM, Technical University of Munich, Munich, Germany. ${ }^{10}$ Roche Innovation Center Munich, pRED, Large Molecule Research, Penzberg, Cermany. "Research Group Microbial Immunology, Leibniz Institute for Natural Product Research and Infection Biology - Hans Knöll Institute, Jena, Germany. ${ }^{12}$ Institute of Microbiology, Friedrich Schiller University, Jena, Germany. ${ }^{13}$ Leibniz Institute DSMZGerman Collection of Microorganisms and Cell Cultures, Braunschweig and German Center for Infection Research, Partner Site Hannover-Braunschweig, Hannover-Braunschweig, Germany. ${ }^{14}$ Department of Experimental Immunology, Helmholtz Centre for Infection Research, Braunschweig, Germany.
\end{abstract}

\begin{abstract}
Th cells integrate signals from their microenvironment to acquire distinct specialization programs for efficient clearance of diverse pathogens or for immunotolerance. Ionic signals have recently been demonstrated to affect T cell polarization and function. Sodium chloride $(\mathrm{NaCl})$ was proposed to accumulate in peripheral tissues upon dietary intake and to promote autoimmunity via the Th17 cell axis. Here, we demonstrate that high-NaCl conditions induced a stable, pathogen-specific, antiinflammatory Th17 cell fate in human T cells in vitro. The p38/MAPK pathway, involving NFAT5 and SCK1, regulated FoxP3 and IL-17A expression in high- $\mathrm{NaCl}$ conditions. The $\mathrm{NaCl}$-induced acquisition of an antiinflammatory Th17 cell fate was confirmed in vivo in an experimental autoimmune encephalomyelitis (EAE) mouse model, which demonstrated strongly reduced disease symptoms upon transfer of $\mathrm{T}$ cells polarized in high- $\mathrm{NaCl}$ conditions. However, $\mathrm{NaCl}$ was coopted to promote murine and human Th17 cell pathogenicity, if T cell stimulation occurred in a proinflammatory and TCF- $\beta$-low cytokine microenvironment. Taken together, our findings reveal a context-dependent, dichotomous role for $\mathrm{NaCl}$ in shaping Th17 cell pathogenicity. $\mathrm{NaCl}$ might therefore prove beneficial for the treatment of chronic inflammatory diseases in combination with cytokine-blocking drugs.
\end{abstract}

\section{Introduction}

Human immune surveillance requires distinct $\mathrm{T}$ cell specialization programs for efficient clearance of diverse pathogens. This is realized by distinct migration patterns as well as cytokine profiles that tailor the responses of $\mathrm{T}$ cells to their respective target antigens (1). The proinflammatory nature of Th17 cells has been strongly associated with the containment of Candida albicans infections as well as with the pathogenesis of autoimmune diseases (2). Consequently, numerous therapies have emerged that target this $\mathrm{T}$ cell subset and its effector functions with striking efficacy (3).

Recently, heterogeneity was revealed within the Th17 cell subset, which also included an antiinflammatory Th17 cell fate $(2,4,5)$.

Authorship note: SH and FP contributed equally to this work. MH and TK contributed equally to this work.

Conflict of interest: The authors have declared that no conflict of interest. Copyright: (5) 2020, American Society for Clinical Investigation.

Submitted: March 3, 2020; Accepted: May 14, 2020; Published: July 27, 2020.

Reference information: J Clin Invest. 2020;130(9):4587-4600.

https://doi.org/10.1172/JCl137786.
A post-activation program characterized by IL-10 expression confers immunosuppressive properties to Th17 cells, which limits the proliferation of bystander $\mathrm{T}$ cells as well as inflammatory functions of innate immune cells $(6,7)$. In addition, ROR- $\gamma$ t- and FoxP3coexpressing $\mathrm{T}$ cells that share both Th17 cell and immunoregulatory Treg identities have been identified as functionally contributing to the containment of inflammation at mucosal surfaces (8-10).

Although this functional dichotomy of pro- and antiinflammatory effects has been well established, the extracellular signals and intracellular mechanisms that instruct this dichotomy of pro- and antiinflammatory Th17 cell fates remain poorly defined and almost exclusively restricted to cytokine effects. For example, IL-1 $\beta$ has been identified as a critical switch factor that determines human Th17 cell pathogenicity by inducing the expression of proinflammatory molecules and suppressing the expression of antiinflammatory molecules (2). In mice, IL-23 licenses Th17 cells for pathogenicity, whereas TGF- $\beta$ drives antiinflammatory Th17 cell responses (11-14).

Sodium chloride $(\mathrm{NaCl})$ represents a critical, yet still largely overlooked, determinant of the human tissue microenvironment with major implications for organ-specific immune regulation, 
allergy, and autoimmunity (15-18). Peripheral tissues, such as the skin, are thought to accumulate $\mathrm{NaCl}$ at high concentrations independently of systemic renal osmolyte regulation. This occurs not only in response to dietary intake but also in diet-independent settings such as in atopic dermatitis or infections (19-21). Naive T cells, which surveil secondary lymphoid organs, have previously been shown to dramatically upregulate IL-17A upon $\mathrm{NaCl}$ exposure in polarizing cytokine conditions $(22,23)$. However, naive $\mathrm{T}$ cells do not patrol peripheral tissues, unlike effector or tissueresident memory $\mathrm{T}$ cells (24-26). Therefore, the direct effect of $\mathrm{NaCl}$ as a determinant of the tissue microenvironment remains to be explored for tissue-homing effector $\mathrm{T}$ cell subsets. In particular, the role of $\mathrm{NaCl}$ in the dichotomous nature of the inflammatory state of Th17 cells remains to be elucidated.

Our data demonstrate that $\mathrm{NaCl}$ shifts Th17 cells toward an antiinflammatory fate. A proinflammatory cytokine microenvironment can, however, divert its antiinflammatory function and instead coopt $\mathrm{NaCl}$ for amplifying Th17 cell pathogenicity. $\mathrm{NaCl}$ therefore exerts divergent effects on Th17 cells depending on the cytokine context.

\section{Results}

$\mathrm{NaCl}$ amplifies Th17 cell effector functions in memory $\mathrm{T}$ cells. We previously demonstrated that $\mathrm{NaCl}$ exerts effects not only on naive $\mathrm{Th}$ cells, as postulated before $(22,23)$, but also on $\mathrm{CD}^{4} 5 \mathrm{RA}^{-}$memory $\mathrm{T}$ cells, in which $\mathrm{NaCl}$ enhanced both IL-17A and IL-4 production, even in the absence of polarizing cytokines (16). We decided to investigate the impact of $\mathrm{NaCl}$ on effector memory $\mathrm{T}$ cells (Tem), which, in contrast to naive and central memory $\mathrm{T}$ cells (Tcm), readily enter peripheral tissues, and thus a $\mathrm{NaCl}$-enriched microenvironment, during their recirculation route or for further differentiation into resident memory $\mathrm{T}$ cells (Trm) $(24,25,27)$. We therefore isolated human $\mathrm{CD}^{+}{ }^{+} \mathrm{CD} 45 \mathrm{RA}^{-} \mathrm{CCR} 7^{-}$Tem cells ex vivo and restimulated them at a low $\mathrm{NaCl}(140 \mathrm{mM})$ or high $\mathrm{NaCl}(185 \mathrm{mM})$ concentration, reflecting a physiological blood or tissue microenvironment, respectively $(16,17)$. We found that IL-17A production and other Th17 cell signature properties, such as ROR- $\gamma$ t, IL-22, and CCR6 expression, strongly increased in high$\mathrm{NaCl}$ conditions (Figure 1, A and B). This enhanced Th17 signature was further supported by a transcriptome-wide analysis, which revealed the enrichment for Th17 cell-associated gene signatures upon restimulation of Th17 cells in the high- $\mathrm{NaCl}$ condition (Figure 1C). Skin Trm cells, which were identified by CD69 and CD103 coexpression, also upregulated IL-17A expression upon in vitro restimulation in the high- $\mathrm{NaCl}$ condition (Figure 1D). Polarizing cytokines, which have previously been shown to induce Th17 cell differentiation and expansion, masked the direct Th17-promoting effects of $\mathrm{NaCl}$ at the effector $\mathrm{T}$ cell level, as we observed no further synergistic effects (Figure 1E). Our data therefore demonstrate that $\mathrm{NaCl}$ directly affects fully differentiated effector $\mathrm{T}$ cells, which readily respond to $\mathrm{NaCl}$ by amplification of Th17 cell-associated effector functions independently of exogenous cytokines.

$\mathrm{NaCl}$ induces antiinflammatory Th17 cell responses. Recently, divergent post-activation fates have been delineated within the Th17 cell lineage, showing a dichotomy of pro- versus antiinflammatory functions $(2,6,7)$. We therefore stimulated ex vivo-isolated human Th17 cells in the presence of low and high $\mathrm{NaCl}$ concentrations to test for coexpression of antiinflammatory molecules. Surprisingly, FoxP3 expression was strongly upregulated in high- $\mathrm{NaCl}$ compared with low- $\mathrm{NaCl}$ conditions, giving rise to IL-17A and FoxP3 double-positive T cells (Figure 2A). This finding was supported by analysis of $\mathrm{T}$ cell clones, which showed further upregulation of both FoxP3 and IL-17A expression in high- $\mathrm{NaCl}$ conditions despite chronic $\mathrm{T}$ cell receptor activation (Supplemental Figure 1, A and B; supplemental material available online with this article; https://doi.org/10.1172/JCI137786DS1). The putatively antiinflammatory Th17 cell phenotype was further corroborated by strong upregulation of the immunosuppressive cytokine TGF- $\beta$ in response to high- $\mathrm{NaCl}$ concentrations (Figure $2 \mathrm{~A})$. ROR- $\gamma \mathrm{t}^{+}$Th17 cells also acquired de novo FoxP3 coexpression upon restimulation in high- $\mathrm{NaCl}$ conditions (Figure 2B), thus displaying a pattern of transcription factors that was previously shown to translate into antiinflammatory functions $(8,10)$. The FoxP3 upregulation induced by $\mathrm{NaCl}$ even exceeded that of ROR- $\gamma$ t upregulation in ex vivo-isolated memory Th cells (Figure 2B). $\mathrm{NaCl}$ exerted its antiinflammatory effects on Th17 cells in a dose-dependent manner over a wide range of $\mathrm{NaCl}$ concentrations, whereas IL-17A upregulation plateaued by only small incremental increases in extracellular $\mathrm{NaCl}$ (Supplemental Figure 2, A-D). To corroborate the antiinflammatory Th17 cell phenotype that was induced by $\mathrm{NaCl}$, we also assessed the expression of other molecules that are associated with immunosuppressive $\mathrm{T}$ cell functions. High- $\mathrm{NaCl}$ conditions increased the expression of other regulatory signature molecules such as IL1O, LAG3, ICOS, and CTLA 4 in Th17 cells (Figure 2C). We performed next-generation RNA-Seq of Th17 cells stimulated in low- or high- $\mathrm{NaCl}$ conditions to interrogate these cells transcriptome-wide for a Treg signature. Gene set enrichment analysis (GSEA) showed a clear enrichment of the Treg signature in Th17 cells stimulated in high- compared with low- $\mathrm{NaCl}$ conditions (Figure 2D). The induction of an antiinflammatory $\mathrm{T}$ cell fate by $\mathrm{NaCl}$ was not restricted to Th17 cells, as it also occurred in Th1 and Th2 cells (Supplemental Figure 3). Tregs, which were isolated ex vivo as $\mathrm{CD} 25^{\text {hi }} \mathrm{CD} 127^{\text {lo }}$ cells, also further increased FoxP3 and TGF- $\beta$ expression upon restimulation in high- $\mathrm{NaCl}$ conditions. This increase was accompanied by ROR- $\gamma$ t and IL-17A upregulation (Supplemental Figure 4), which, according to previous reports, might abrogate the overall antiinflammatory function of Tregs (28-30). This is in contrast to the impact of $\mathrm{NaCl}$ on other Th cell subsets, which acquired an antiinflammatory profile instead (Supplemental Figure 4).

Consistent with our finding that $\mathrm{NaCl}$ was sufficient to promote the antiinflammatory Th17 cell fate upon restimulation of memory $\mathrm{T}$ cells, we also observed a reduction in proinflammatory IFN- $\gamma$ coexpression in IL-17A-producing T cell clones (Figure 2E). Together, these data indicate by multiple phenotypic and transcriptional readouts that $\mathrm{NaCl}$ might promote an antiinflammatory phenotype of human Th17 cells.

NaCl-induced FoxP3 upregulation, but not IL-17A upregulation, can be stably maintained in the absence of high $\mathrm{NaCl}$ concentrations. Immune surveillance by effector $\mathrm{T}$ cells is realized by their continuous recirculation through the blood, peripheral tissues, and secondary lymphoid organs. Considering the compartmentalization of $\mathrm{NaCl}$ concentrations in peripheral tissues (17), circulating effector $\mathrm{T}$ cells are exposed to repeated fluctuations of $\mathrm{NaCl}$ levels in their microenvironment. We therefore asked whether the changes 
A Effector memory $T$ helper cells (CD45RA-CCR7-)
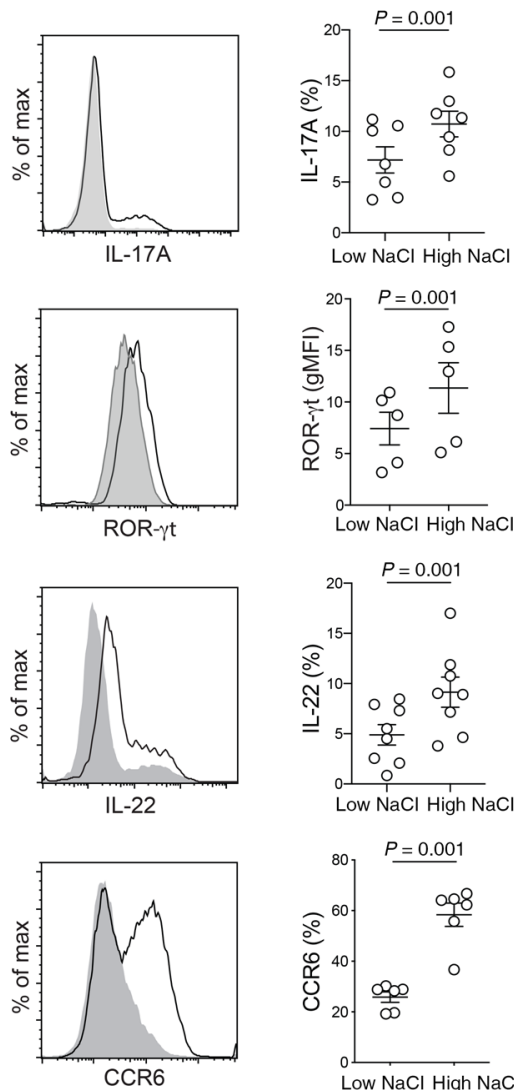

$\rightleftarrows$ Low $\mathrm{NaCl}$
B

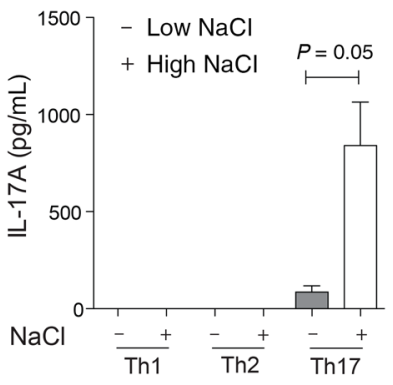

D

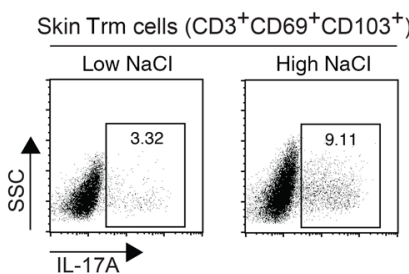

E
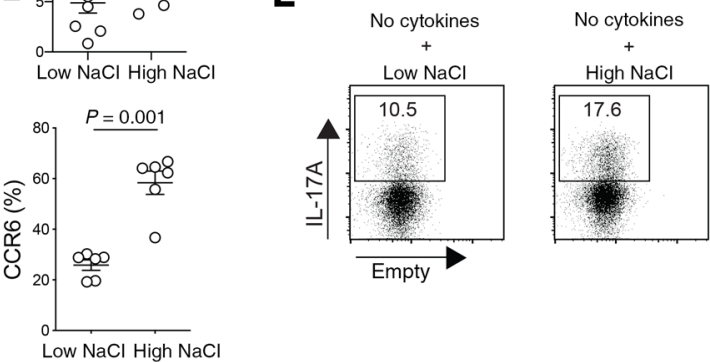

C
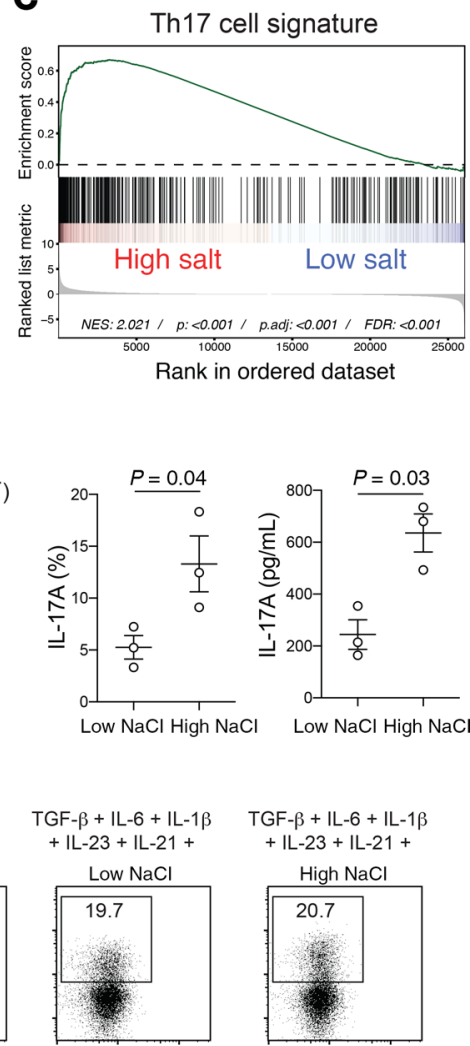

TGF- $\beta+$ IL- $6+$ IL- $1 \beta$ $+\mathrm{IL}-23+\mathrm{IL}-21+$ High $\mathrm{NaCl}$

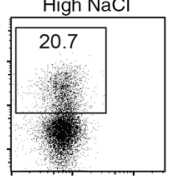

Figure 1. $\mathrm{NaCl}$ promotes the Th17 cell program in human effector memory Th cells independently of polarizing cytokines. (A-C) Human effector memory Th cells were FACS sorted from fresh human PBMCs as CD4+CD14-CD45RA-CCR7- T cells and stimulated for a total culture period of 5 days in low- or high- $\mathrm{NaCl}$ conditions with CD3 and CD28 mAbs (48 hours plate-bound). (A) Intracellular staining and FACS on day 5 after PMA and ionomycin restimulation for 5 hours. FACS staining of an individual experiment (left) and cumulative data are shown. Each circle indicates an individual donor. gMFI, geometric MFI; max, maximum. (B) ELISA analysis of cell culture supernatants analyzed on day 5 after stimulation with PdBU and CD3 mAb for 8 hours ( $n=3$ ). (C) Transcriptome analysis and GSEA (CSE52260) of genes related to the Th17 signature in Th17 cells stimulated as in A (67). (D) Skin CD3 ${ }^{+} \mathrm{T}$ cells were isolated from human abdominal skin by overnight collagenase digestion followed by FACS sorting. The cells were stimulated for 48 hours with CD3 and CD28 mAbs in low- or high- $\mathrm{NaCl}$ conditions followed by intracellular cytokine staining after PMA and ionomycin restimulation. A representative experiment (left) and cumulative data are shown (middle). ELISA analysis (right) of cell culture supernatants from skin CD3+ $T$ cells restimulated with PdBU and CD3 mAbs for 8 hours after 48 hours of CD3 and CD28 mAb stimulation in low- and high- $\mathrm{NaCl}$ conditions. Data were normalized to 20,000 T cells. Each circle indicates an individual donor. (E) FACS analysis performed as in $\mathbf{A}$ in the absence or presence of Th17-polarizing cytokines. The data are representative of 3 donors.

(A, B, and D) A 2-tailed, paired Student's $t$ test was performed for comparisons between 2 groups.

in Th17 cell functions observed above were contingent on the acute presence of $\mathrm{NaCl}$, or whether they could be stably maintained after the cells enter low- $\mathrm{NaCl}$ microenvironments.

Furthermore, the stable maintenance of increased human FoxP3 expression in $\mathrm{T}$ cells over time and in changing microenvironments would stress the antiinflammatory human $\mathrm{T}$ cell functionality, whereas transient FoxP3 upregulation instead correlates with human $\mathrm{T}$ cell activation according to previous reports $(31,32)$.

To this end, we subjected Th17 cells that were restimulated in high- $\mathrm{NaCl}$ conditions to repeated restimulations in low- $\mathrm{NaCl}$ conditions. Whereas NaCl-mediated IL-17A upregulation was not maintained upon repeated polyclonal TCR restimulation in the absence of high $\mathrm{NaCl}$ levels, increased FoxP3 expression was stably maintained during 2 consecutive rounds of TCR restimulation, even after withdrawal of $\mathrm{NaCl}$ (Figure 3, A and B). However, this increased expression was not maintained for TGF- $\beta$ (Figure 3 C).

Collectively, these data indicate that the increase in Th17 cell effector functions, such as IL-17A production, is contingent on the acute presence of $\mathrm{NaCl}$ in the extracellular microenvironment, whereas the antiinflammatory effect of $\mathrm{NaCl}$ on the Th17 cell phenotype persists over the long term, even upon reentry into a low- $\mathrm{NaCl}$ microenvironment such as the blood.

NFAT5 and SGK1 regulate FoxP3 and IL-17A expression in memory $\mathrm{T}$ cells in high-NaCl conditions. We next addressed the molecular mechanism by which $\mathrm{NaCl}$ affects human effector Th17 cells. Hyperosmotic stress can be sensed by mammalian cells through the p38/MAPK pathway and its downstream targets NFAT5 and SGK1 $(33,34)$. This pathway has recently been shown to confer 
A
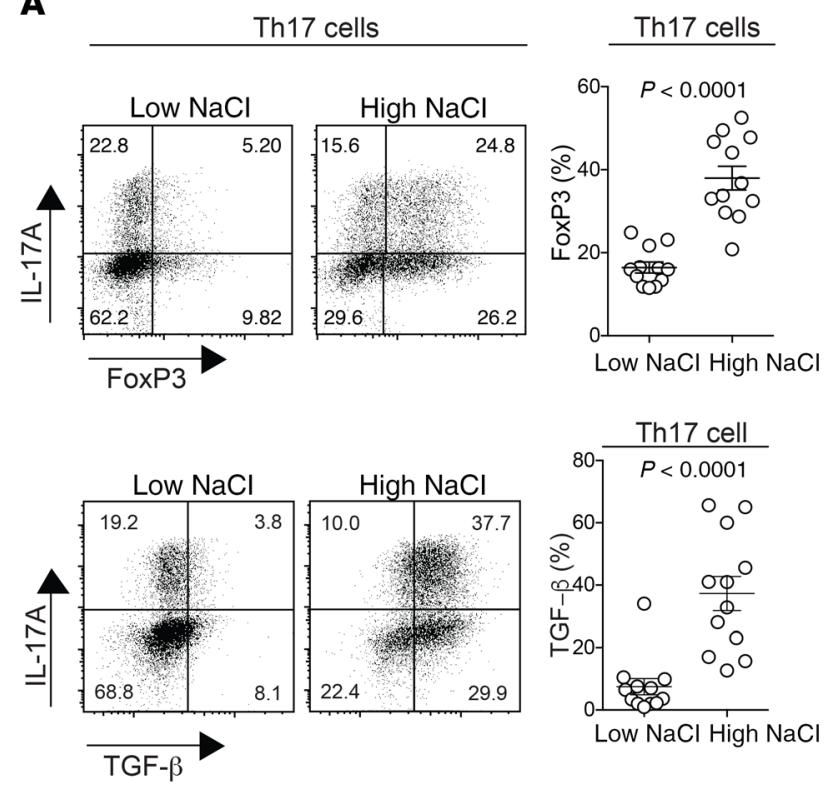

B
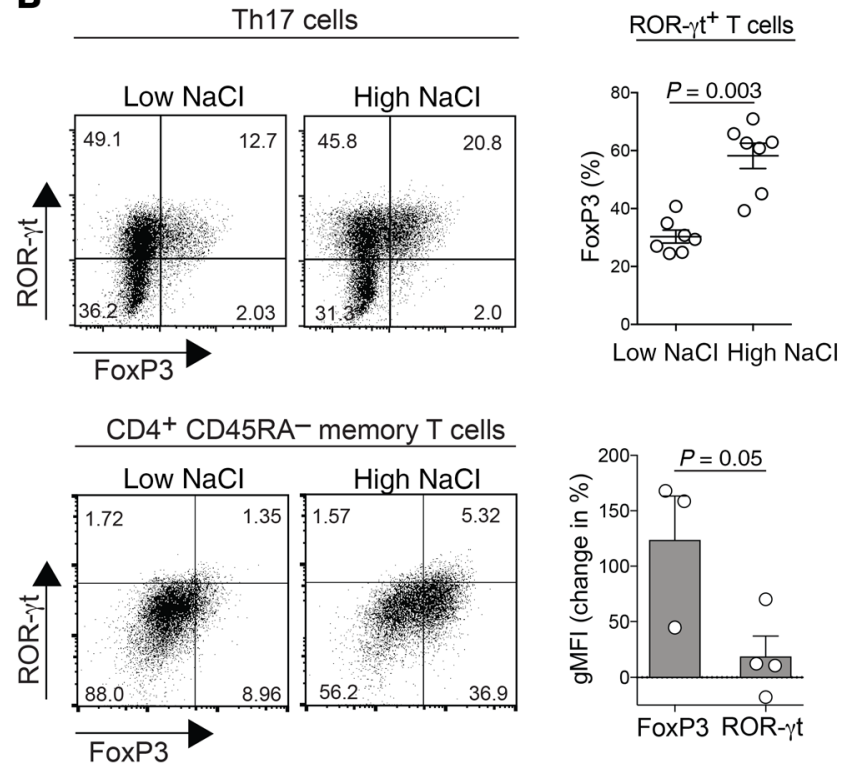

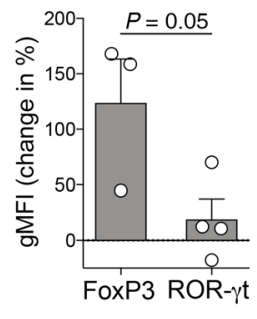

C

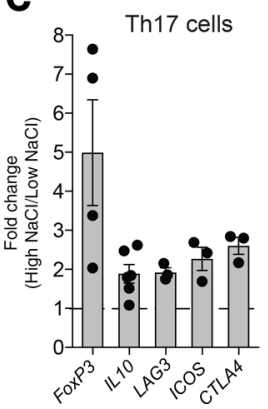

D

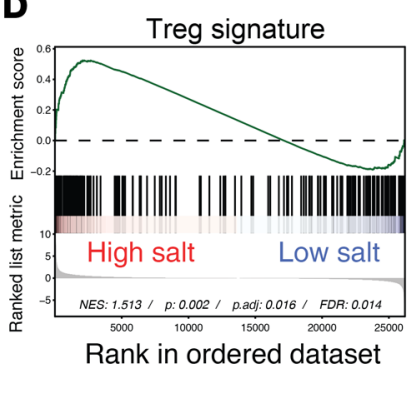

E

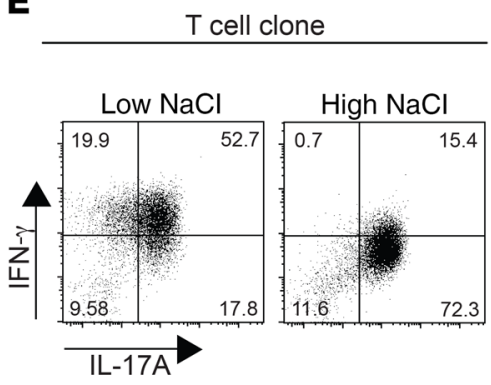

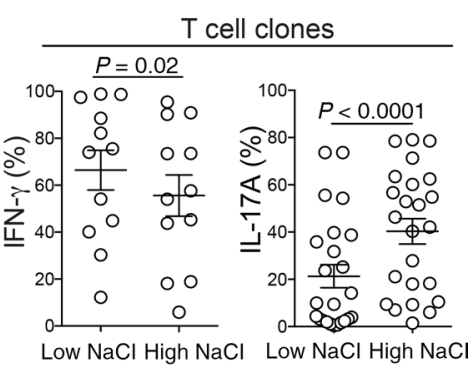

Figure 2. Human Th17 cells acquire antiinflammatory functions upon restimulation in high-NaCl conditions. (A) CD4+CD14-CD45RA-CCR6+CCR4+CXCR3- Th17 cells were sorted by flow cytometry from fresh human PBMCs as T cells and stimulated for a total culture period of 5 days in high-or low-NaCl conditions with CD3 and CD28 mAbs (48 hours plate-bound). Results for intracellular staining and FACS analysis on day 5 following PMA and ionomycin restimulation are shown. A representative FACS plot and cumulative data with each circle representing an individual donor are shown. (B) Intracellular staining for transcription factors followed by FACS analysis of T cells isolated and stimulated for 5 days with CD3 and CD28 mAbs (48 hours plate-bound). Top panel: Circles indicate individual blood donors. Bottom panel: Change in transcription factor expression in T cells stimulated in high- versus low-NaCl conditions ( $n=3-4)$. (C) qRT-PCR analysis of Th17 cells stimulated as in $\mathbf{A}(n=3-6)$. A 2-tailed Student's $t$ test was performed for comparisons of high- versus low-NaCl conditions; $P<0.05$ for each of the transcripts shown. (D) GSEA for Treg-associated genes (CEO GSE18893) in Th17 cells cultured in low- or high-NaCl conditions for 5 days (48 hours CD3/CD28 mAbs). (E) T cell clones were generated from CD4+CD14-CD45RA-CCR6 +CCR4+CXCR3- $T$ cells, which were enriched for Th17 cells, and then restimulated in low or high $\mathrm{NaCl}$ concentrations, as in A. Intracellular staining and FACS analysis are shown. A representative FACS plot and cumulative data are shown. Each circle represents a separate T cell clone. A 2-tailed Student's $t$ test was used for comparisons between 2 groups (A-C, and $\mathbf{E})$.

pathogenicity to developing Th17 cells $(22,23)$. We therefore interrogated the same pathway for its impact on $\mathrm{NaCl}$-mediated regulation of the antiinflammatory human Th17 cell phenotype, which we have unraveled above. Pharmacological blockade of p38 signaling abrogated $\mathrm{NaCl}$-induced IL-17A and FoxP3 upregulation in effector Th17 cells (Figure 4A). Similar to previous reports that tested the effect of $\mathrm{NaCl}$ on naive $\mathrm{T}$ cells in Th17polarizing cytokine conditions (22), this study found that effector Th17 cells also upregulated the expression of both NFAT5 and its downstream target $S G K 1$ upon restimulation in high- $\mathrm{NaCl}$ conditions, as shown by quantitative real-time PCR (qRT-PCR) analysis (Figure 4B). shRNA-mediated silencing of both genes abrogated their $\mathrm{NaCl}$-induced upregulation, demonstrating that NFAT5 and SGK1 regulated IL-17A as well as FoxP3 expression in hypersaline conditions (Figure $4 \mathrm{C}$ ). These findings were also supported by the reduced expression of TGF- $\beta$ and ROR- $\gamma \mathrm{t}$ following blockade with SGK1 (Supplemental Figure 5). Consistent with this antiinflammatory Treg-like Th17 cell commitment, we identified binding sites for NFAT5 in the TGFB1, STAT5, and FOXP3 promoter regions using a previously published ChIPSeq data set (Supplemental Figure 6 and ref. 35). Overall, these results demonstrate a role for the p38/MAPK/NFAT5/SGK1 axis not only for the regulation of IL-17A but also for FoxP3 expression in effector Th17 cells in high- but not low- $\mathrm{NaCl}$ conditions. Importantly, this reveals a distinct modulation of transcriptional programs depending on extracellular $\mathrm{NaCl}$ concentrations.

A proinflammatory cytokine microenvironment abrogates the induction of an antiinflammatory Th17 cell phenotype by $\mathrm{NaCl}$. The $\mathrm{NaCl}$-induced antiinflammatory effects on human Th17 cells were unexpected, considering that $\mathrm{NaCl}$ has been previously reported 
A

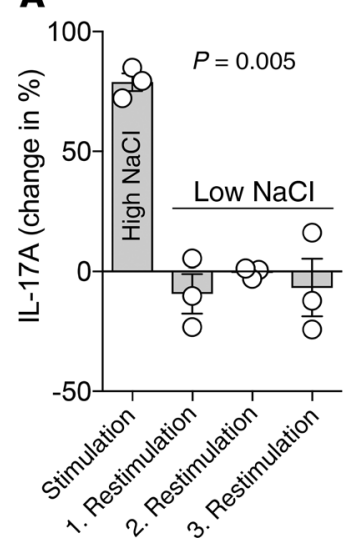

B

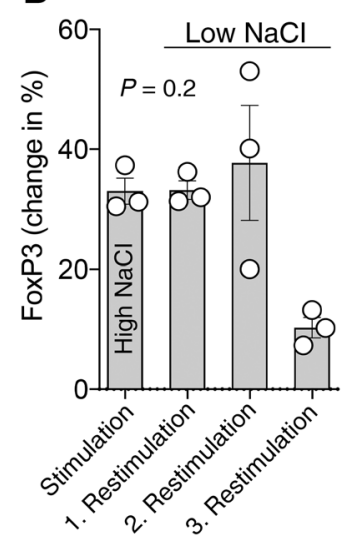

C

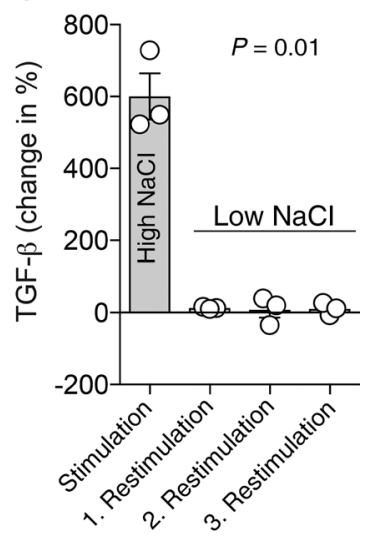

Figure 3. $\mathrm{NaCl}$-induced FoxP3 upregulation in Th17 cells is stably maintained after entering low- $\mathrm{NaCl}$ conditions, whereas IL-17A upregulation is transient. (A-C) Human Th17 cells (CCR6 ${ }^{+}$CCR4 ${ }^{+}$CXCR3-) were restimulated with $\mathrm{CD} 3$ and $\mathrm{CD} 28$ mAbs (48 hours plate-bound) in low or high $\mathrm{NaCl}$ concentrations for a total culture period of 5 days. Intracellular staining and FACS analysis after PMA and ionomycin restimulation are shown. The Th17 cells were restimulated again with $\mathrm{CD} 3$ and CD28 mAbs up to 3 times for 5 days, with 2 additional resting days between the restimulations $(n=3)$. The change of the geometric mean of FoxP3 expression (B) compared with control Th17 cells that were restimulated once in low- $\mathrm{NaCl}$ conditions (C) are shown. One-way ANOVA was used for comparisons among multiple groups. to induce pathogenic Th17 cell differentiation from naive $\mathrm{T}$ cell precursors $(22,23)$. Since human Th17 cell differentiation requires the presence of several polarizing cytokines, including IL- 6 and IL-1 $\beta$, which have previously been shown to instruct $\mathrm{T}$ cell pathogenicity $(2,36)$, we tested the effect of high $\mathrm{NaCl}$ concentrations on effector Th17 cells in the presence of individual proinflammatory cytokines as well as their combinations (5). IL- 6 and IL-1 $\beta$ suppressed FoxP3 expression, which is in line with previous reports (refs. 37-40 and Figure 5, A and B). We found that the presence of these Th17-polarizing cytokines also abrogated $\mathrm{NaCl}$-induced FoxP3 upregulation, giving rise to a proinflammatory Th17 cell phenotype (Figure 5, A and B). Autocrine TGF- $\beta$ secretion was also suppressed by these proinflammatory cytokines in high- $\mathrm{NaCl}$ conditions (Figure 5, A and C). Both antiinflammatory molecules were likewise inhibited in high- $\mathrm{NaCl}$ conditions if IL-23 and IL-21 joined the Th17-polarizing cytokines (Figure 5, A and B). TGF- $\beta$ was relevant for concomitant FoxP3 upregulation in high- $\mathrm{NaCl}$ conditions, as shown by reduced FoxP3 expression levels upon TGF- $\beta$ depletion with neutralizing Abs (Figure 5C). This also stressed that secreted TGF- $\beta$ was bioactive, enabling its activity in an autocrine manner. $\mathrm{NaCl}$-induced IL-17A upregulation was not further enhanced in effector Th17 cells in the presence of these proinflammatory cytokines (Figure 5A and Figure 1E).

Together, these data indicate a dominant role for proinflammatory cytokines over the antiinflammatory effects that $\mathrm{NaCl}$ directly exerts on effector $\mathrm{T}$ cells. $\mathrm{NaCl}$ has, therefore, a context-dependent function in the complex immune microenvironment that can translate into divergent Th17 cell fates.

The antigen specificity of Th17 cells determines whether pro- or antiinflammatory effects are induced by $\mathrm{NaCl}$. We previously demonstrated that distinct cytokine priming conditions are required for the generation of human Th17 cells, which differ in their pathogen specificities (2). In particular, IL-1B is required for C. albicans-specific Th17 cell polarization but is dispensable for Staphylococcus aureus-specific Th17 cell polarization $(2,4)$. This translates into pro- versus antiinflammatory Th17 cell functions, respectively (6). Given that IL-1 $\beta$ was able to abrogate the antiinflammatory effect of $\mathrm{NaCl}$ on effector Th17 cells, we tested whether the requirement for IL-1 $\beta$ in generating C. albicans-specific Th17 cells would render these cells more resistant to the antiinflammatory effects of $\mathrm{NaCl}$ than S. aureus-specific Th17 cells. We isolated human effector Th17 cells from the blood according to the differential expression of surface markers ex vivo and restimulated them with C. albicans- or $S$. aureus-pulsed monocytes $(2,41)$. The C. albicans- and S. aureusspecific Th17 cells that were isolated, as confirmed by CFSE dilution, were then cloned and assessed for antiinflammatory factors. We observed a strong upregulation of FoxP3 expression in the $S$. aureus-specific $\mathrm{Th} 17$ cell clones in response to high- $\mathrm{NaCl}$ restimulation. In contrast, the C. albicans-specific Th17 cell clones were resistant to the effects of high $\mathrm{NaCl}$ concentration on FoxP3 expression. We applied the same approach to study TGF- $\beta$ expression and found that it was also upregulated in S. aureus- but not C. albicans-specific Th17 cell clones upon restimulation in high- $\mathrm{NaCl}$ conditions (Figure 6A). These findings demonstrate that $\mathrm{NaCl}$ exerts divergent effects on the functional responses in effector $\mathrm{T}$ cells depending on the microbial antigen specificities of the effector $\mathrm{T}$ cells.

We then addressed the underlying mechanism. We hypothesized that the priming requirement of naive $\mathrm{T}$ cells for proinflammatory IL-1 $\beta$, which we discovered previously (2), renders the emerging C. albicans-specific Th17 cells resistant to the antiinflammatory effects of $\mathrm{NaCl}$. We therefore reconstructed C. albicans-specific $\mathrm{T}$ cell priming in vitro by coculturing naive CFSElabeled $\mathrm{T}$ cells and autologous monocytes pulsed with C. albicans in the presence or absence of IL-1 $\beta$-blocking Abs as described previously $(2,42)$. Likewise, $S$. aureus-specific T cell differentiation was performed in the presence or absence of recombinant IL-1 $\beta$ to assess whether supplementation with exogenous IL-1 $1 \beta$ renders $S$. aureus-specific naive $\mathrm{T}$ cells resistant to FoxP3 upregulation during their priming phase. Proliferating $\mathrm{CFSE}^{\text {lo }} \mathrm{T}$ cells were cloned and then restimulated in low- or high- $\mathrm{NaCl}$ conditions. Interestingly, the in vitro-polarized C. albicans-specific $\mathrm{T}$ cell clones that had been generated in the presence of IL-1 $\beta$-blocking Abs upregulated FoxP3 to a much greater degree in response to $\mathrm{NaCl}$ than did $\mathrm{T}$ cell clones polarized by C. albicans in non-neutralizing conditions (Figure 6B). This demonstrates that the C. albicans-specific Th17 cells were instructed by IL-1 $\beta$ during their differentiation process to resist the antiinflammatory effects of $\mathrm{NaCl}$. The in vitro-polarized $S$. aureus-specific Th17 cells resisted FoxP3 upregulation in high- $\mathrm{NaCl}$ conditions only if priming occurred in the presence of exogenous IL-1 $\beta$. Taken together, these results demonstrate that the dichotomous microbe-specific responses of $\mathrm{Th} 17$ cells toward $\mathrm{NaCl}$ depend on the differential priming requirements of these cells for IL-1 $1 \beta$. 
A

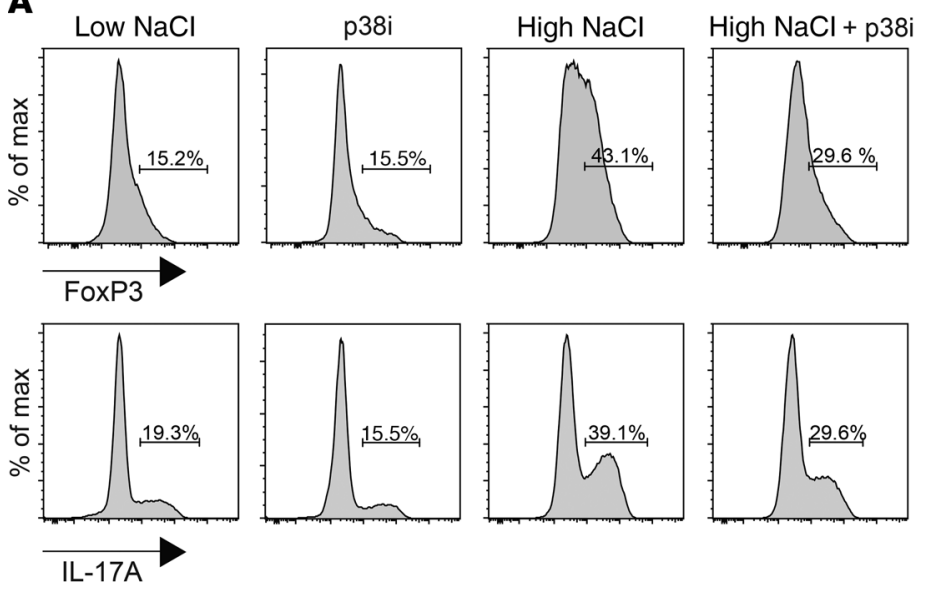

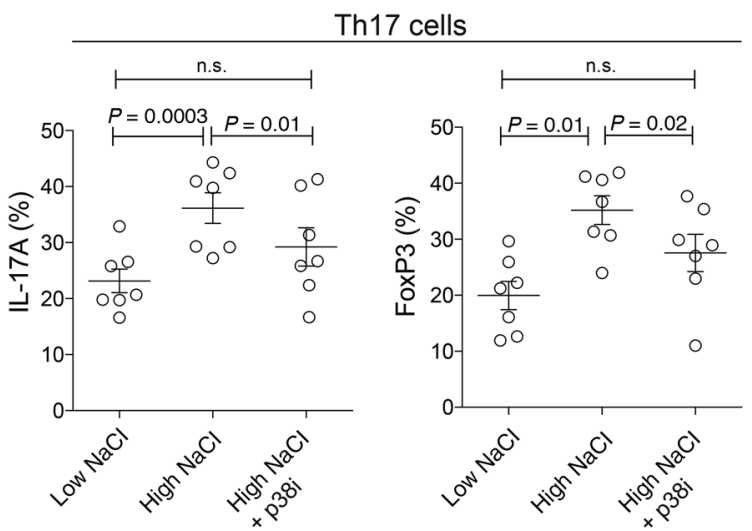

B

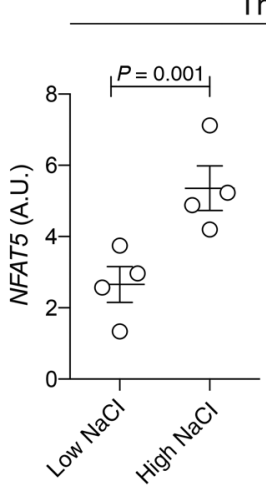

Th17 cells

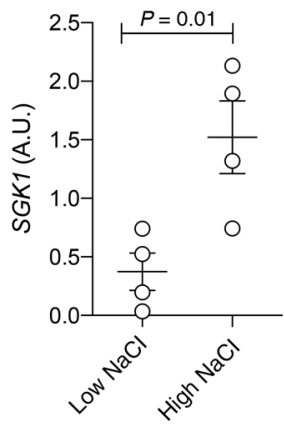

C

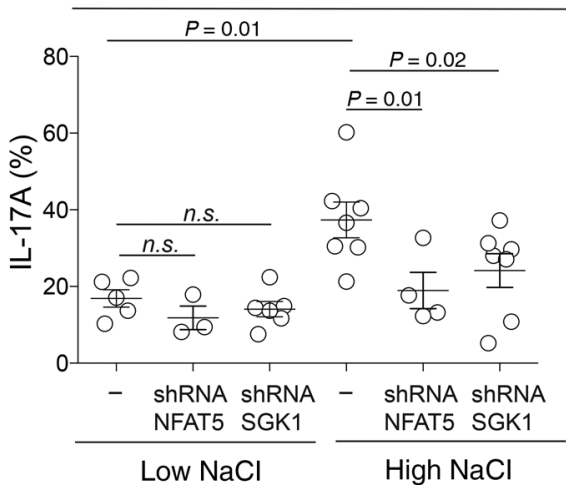

Th17 cells

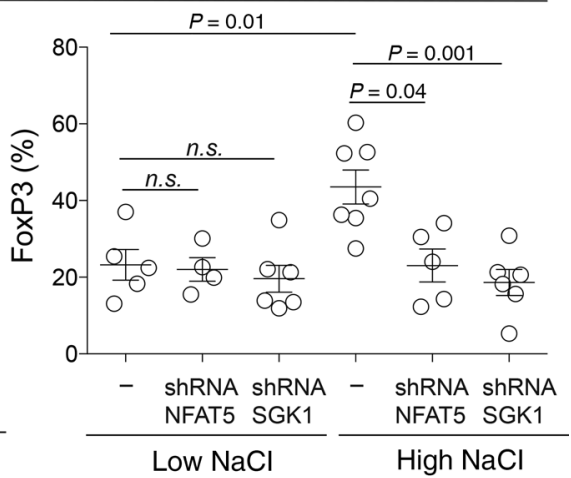

Figure 4. NFAT5 and SGK1 are engaged in the regulation of FoxP3 and IL-17A expression in high- but not low-NaCl conditions. (A) Human Th17 cells (CCR6 ${ }^{+}$CCR4 ${ }^{+} \mathrm{CXCR3}^{-}$) were restimulated in high or low $\mathrm{NaCl}$ concentrations in the presence or absence of a pharmacological inhibitor of p38 (p38i, SB202190) for a total culture period of 5 days with CD3 and CD28 mAbs (48 hours plate-bound). Results for intracellular staining and FACS analysis on day 5 after PMA and ionomycin restimulation are shown. Representative FACS data (left) and cumulative data (right) are shown. Gates were set according to the unstained controls. A 2-tailed Student's $t$ test was used for comparisons between 2 groups. (B) qRT-PCR analysis of Th17 cells on day 5 isolated and stimulated as in A. (C) Intracellular staining and FACS analysis after restimulation in low- or high-NaCl conditions for 5 days in the presence or absence (scrambled shRNA) of shRNA-mediated silencing of NFAT5 and SGK1. Each circle represents an individual blood donor. One-way ANOVA was used for comparisons between multiple groups (FoxP3, $P<0.0004$; IL-17A, $P<0.001$ ).

High-NaCl conditions reduce the pathogenicity of murine Th17 cells in an experimental autoimmune encephalomyelitis mouse model but promote pathogenicity in the absence of TGF- $\beta$. It has previously been shown that a high- $\mathrm{NaCl}$ diet can translate into autoimmune inflammation via the Th17 cell axis (43). In particular, changes in the gut microbiome in response to dietary $\mathrm{NaCl}$ have been shown to affect Th17 cell polarization (43). However, whether $\mathrm{NaCl}$ directly regulates Th17 cell pathogenicity in vivo remains unknown. Considering the antiinflammatory Th17 cell phenotype observed in high- $\mathrm{NaCl}$ conditions in vitro, we decided to investigate its overall impact on autoimmune pathogenesis in vivo in an adoptive $\mathrm{T}$ cell transfer mouse model of experimental autoimmune encephalomyelitis (EAE).

Several distinct cytokine conditions have been identified previously for efficient murine Th17 cell priming (44). In accordance with previous reports $(38,40,45,46)$, the combination of TGF- $\beta$ with various proinflammatory cytokines, such as IL-6, IL-23, and IL-1 $\beta$, as well as their combinations, efficiently induced IL-17A compared with control conditions in the absence of polarizing cytokines (ThO) (Figure 7, A and B). Interestingly, high- $\mathrm{NaCl}$ conditions increased FoxP3 expression, giving rise to IL-17A/ FoxP3-coexpressing murine $\mathrm{CD}^{+} \mathrm{T}$ cells. This was accompanied by IL-17A downregulation (Figure 7, A and B). To test whether high- $\mathrm{NaCl}$ conditions reduced the pathogenicity of these Th17 cells in vivo, we adoptively transferred myelin oligodendrocyte glycoprotein-reactive ( $\mathrm{MOG}_{35-55}$-reactive) T cells into RAG-knockout mice to establish the adoptive transfer EAE mouse model. Naive $\mathrm{T}$ cells $\left(\mathrm{CD} 4^{+} \mathrm{CD} 44^{\text {lo }}\right.$ Foxp3.gfp $\left.{ }^{-}\right)$were sorted using FACS from 2D2 transgenic Foxp3.gfp reporter mice and stimulated for 3.5 days with anti-CD3 and anti-CD28 Abs and TGF- $\beta$ (2 ng/ $\mathrm{mL})$ plus IL-6 $(25 \mathrm{ng} / \mathrm{mL})$, with or without supplementation of $40 \mathrm{mM} \mathrm{NaCl}$. These in vitro-differentiated Th17 cells were thoroughly washed before adoptive transfer in equal numbers $(2 \times$ $10^{6}$ viable cells per recipient) into immunodeficient Rag1 $^{-/-}$mice that received $200 \mathrm{ng}$ pertussis toxin (PTx) i.v. on the day of and 2 days after transfer. The T cells polarized with TGF- $\beta$ plus IL-6 in high- $\mathrm{NaCl}$ conditions did not induce EAE, in contrast to their TGF- $\beta$-plus-IL-6-polarized counterparts, which were stimulated in low- $\mathrm{NaCl}$ conditions (Figure $7 \mathrm{C}$ ). The lack of EAE induction in 
A
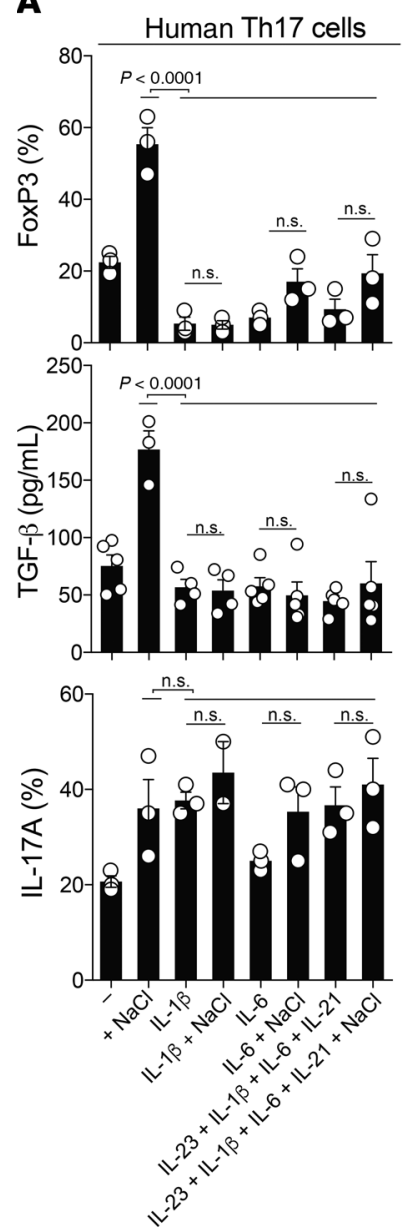

Figure 5. Proinflammatory cytokines abrogate the antiinflammatory switch in the Th17 cell phenotype that is induced in high- $\mathrm{NaCl}$ conditions. (A) FACS analysis (FoxP3, IL-17A) and ELISA (TCF- $\beta$ ) of human Th17 cells stimulated with CD3 and CD28 mAbs for 48 hours in high- or low- $\mathrm{NaCl}$ conditions for a total culture period of 5 days. $P<0.0001$, by 1-way ANOVA (FoxP3 and TCF- $\beta$ ); $P=0.03$, by 1-way ANOVA (IL-17A). (B) qRT-PCR analysis of human Th17 cells on day 5 after stimulation with CD3 and CD28 mAbs for 48 hours in high- or low- $\mathrm{NaCl}$ conditions and the presence or absence of Th17-polarizing cytokines. $P=0.01$ and $P=0.02$, by 1-way ANOVA. (C) FACS analysis performed with cells treated as in $\mathbf{B}$. $P=0.0004$ and $P=0.05$, by 1 -way ANOVA. \pm , in the presence or absence of; $\pm \mathrm{NaCl}$, in high- or low- $\mathrm{NaCl}$ conditions.

high- $\mathrm{NaCl}$ conditions was accompanied by a reduced accumulation of IL-17A $\mathrm{A}^{+} \mathrm{T}$ cells in the CNS compared with the spleen upon ex vivo T cell analysis (Supplemental Figure 7, A and B). Collectively, these data provide evidence that $\mathrm{NaCl}$ can lead to reduced autoimmune disease by directly effecting Th17 cell polarization.

Efficient murine Th17 cell priming has also been previously reported in the absence of exogenous TGF- $\beta$ (47). In the presence of cytokine combinations containing IL-1 $\beta$, IL-23, or IL-6, high- $\mathrm{NaCl}$ conditions did not allow for FoxP3 upregulation but strongly induced IL-17A production, thus promoting the pathogenic murine Th17 cell phenotype, an finding in line with previous reports (Figure 7, D and E, and refs. 22, 23). Autocrine TGF- $\beta$ production was below the detection level (data not shown). Adoptive transfer of murine $\mathrm{T}$ cells polarized in these cytokine conditions resulted in relatively early and increased disease symptoms if $\mathrm{T}$ cell priming occurred in high- rather than low- $\mathrm{NaCl}$ conditions (Figure 7F). This is consistent with previous reports suggesting a pathogenic effect of $\mathrm{NaCl}$ on autoimmunity. Cumulatively, these data reveal that $\mathrm{NaCl}$ can exert divergent effects on autoimmune disease in the EAE mouse model by differential regulation of Th17 cell pathogenicity via the TGF- $\beta$ switch. This cytokine-mediated switch in the ability of $\mathrm{NaCl}$ to induce disease in the EAE model was mirrored by reciprocal accumulation of $\mathrm{FoxP}^{+}$or $\mathrm{IL}-17 \mathrm{~A}^{+} \mathrm{T}$ cells in the CNS upon adoptive transfer of $\mathrm{NaCl}$-treated $\mathrm{T}$ cells that were cultured in high- $\mathrm{NaCl}$ conditions that differed in the presence of TGF- $\beta$ (Supplemental Figure 7, C and D).

\section{Discussion}

The ionic composition of the tissue microenvironment represents a critical, but so far largely overlooked, determinant of physiological and pathological tissue-specific $\mathrm{T}$ cell effector responses (16, $48,49)$. Although dietary $\mathrm{NaCl}$ intake might influence local tissue concentrations, its body-wide differential distribution in homeostatic conditions exposes the circulating and resident immune cells to distinct $\mathrm{NaCl}$ microenvironments. $\mathrm{NaCl}$ has previously been highlighted as a novel and highly potent driver of Th17 cell differentiation and thus autoimmunity $(22,23)$. Our data support these findings but provide another layer of complexity that leads to divergent conclusions. We have revealed a dual contextdependent function of $\mathrm{NaCl}$ with respect to $\mathrm{T}$ cell fates, which translates into pro- and antiinflammatory Th17 cell effector functions. This finding has implications for the pathogenesis and treatment of chronic inflammatory diseases and for protective immunity.

We demonstrated that $\mathrm{NaCl}$ promoted Th17 cell functions at the effector $\mathrm{T}$ cell level independently of exogenous polarizing cytokines. Surprisingly, the effect on effector Th17 cells was accompanied by a strong and stable induction of FoxP3 expression upon direct restimulation with $\mathrm{NaCl}$. Expression of antiinflammatory effector molecules such as TGF- $\beta$ was also strongly induced by $\mathrm{NaCl}$, supporting an overall switch toward an antiinflammatory $\mathrm{T}$ cell fate with concomitant maintenance of the Th17 cell identity. The antiinflammatory Th17 cell functionality adapted in a dosedependent manner to its $\mathrm{NaCl}$ microenvironment, whereas IL-17A production reached a plateau with only small incremental increases in extracellular $\mathrm{NaCl}$ concentrations. In contrast, proinflammatory IFN- $\gamma$ coproduction was downregulated, which was consistent with the previously reported shift from Th1 to Th2 responses in high-salt conditions $(16,49)$. This suggests that high $\mathrm{NaCl}$ concentrations, which are encountered in peripheral tissues (17), primarily regulate and further modulate the antiinflammatory functional repertoire of Th17 cells, whereas IL-17A expression levels can become saturated even before entering tissue microenvironments. Cumulatively, these findings support the view that antiinflammatory Th17 cell features prevail in $\mathrm{NaCl}$-enriched tissue microenvironments.

Our findings revealed that transcriptional networks instructing specific $\mathrm{T}$ cell identities differ depending on the $\mathrm{NaCl}$ concentration in the microenvironment. Mechanistically, we demonstrated that NFAT5 and its downstream kinase SGK1 are critical for the antiinflammatory switch in Th17 cells induced by high- $\mathrm{NaCl}$ conditions. Interestingly, expression of FoxP3 and IL-17A was not regulated by NFAT5 or SGK1 in low- $\mathrm{NaCl}$ conditions but rather 
A

Th17 cell clones

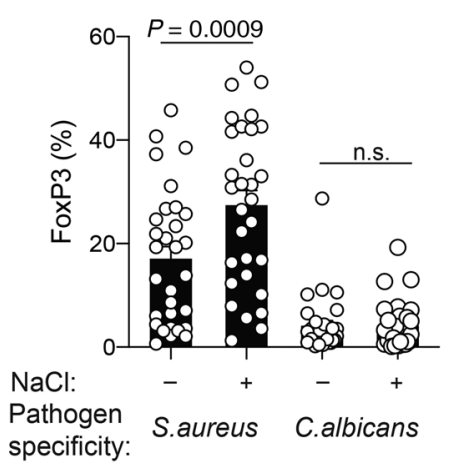

Th17 cell clones

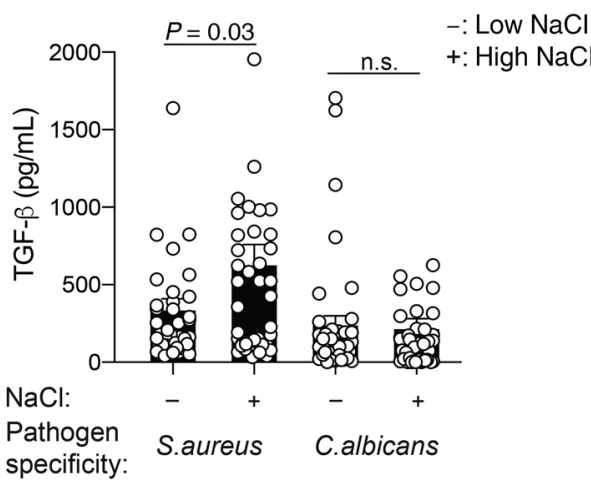

B Naive $T$ cells + monocytes
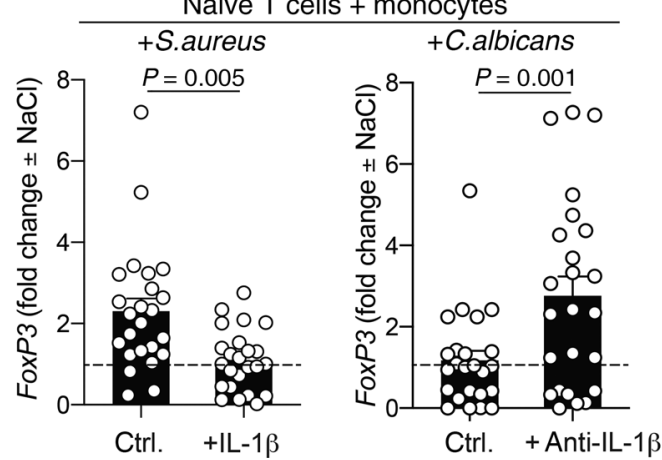

Figure 6. The microbial antigen specificity of human Th17 cells determines whether pro- or antiinflammatory effects are promoted by $\mathrm{NaCl}$. (A) Human Th17 cells were sorted by flow cytometry, labeled with CFSE, and restimulated with autologous monocytes (2:1 ratio) that had been pulsed for 3 hours with S. aureus (DSM799) or C. albicans (SC5314) lysates before glutardehyde fixation as described previously (2). CFSE ${ }^{10}$ Th17 cells were FACS sorted on day 4 and then cloned. The $T$ cell clones were restimulated on days 12 to 14 with CD3 and CD28 for 48 hours and analyzed after a 5-day culture period in low- or high- $\mathrm{NaCl}$ conditions before intracellular staining and FACS analysis or ELISA of the culture supernatants. (B) Naive T cells were sorted as CD4+CD45RA ${ }^{+} T$ cells and stimulated with autologous monocytes that were pulsed with microbial lysates in the presence or absence of endogenously produced or recombinant IL-1 $\beta$. CFSE ${ }^{10} T$ cells were FACS sorted and cloned on day 9 . The $T$ cell clones were restimulated in low- or high- $\mathrm{NaCl}$ conditions as in $\mathbf{A}$. The fold change of FoxP3 expression in high- versus low- $\mathrm{NaCl}$ conditions is shown. ctrl., control. An unpaired 2-tailed Student's $t$ test was used for comparisons between 2 groups. Circles indicate individual T cell clones. upon restimulation in high- $\mathrm{NaCl}$ conditions. Transcriptional regulation should therefore be revisited within the context of tissue $\mathrm{NaCl}$ concentrations, which are not currently reflected by $\mathrm{NaCl}$ concentrations in standard cell culture media. We anticipate that this adaptation to physiological ionic contexts will unravel many more transcriptional pathways that have been overlooked thus far in standard cell culture media conditions. A human salt atlas depicting the body-wide differential distribution of $\mathrm{NaCl}$ concentrations will be important to establish, in order to map the tissue distribution of this important immunomodulator in health and disease as well as in dietary contexts.

Previous studies support our observation that SGK1 expression is associated with an antiinflammatory T cell identity. SGK1 has previously been shown to be more strongly expressed in peripherally induced Tregs (pTregs) than in Th17 or naive T cells in mice and is known to be induced by TGF- $\beta$ (50). Furthermore, we and others have demonstrated that SGK1 promotes Th2 cell development over Th1 cell development in mice and humans and thus promotes allergic pathogenesis over autoimmune pathogenesis $(16,51)$. However, in Tregs, SGK1 was previously shown to disarm the immunosuppressive functionality and to even suppress the induction of FoxP3 expression $(23,50)$. These effects might particularly apply to thymus-derived natural Tregs, since induced Tregs remain suppressive in high- $\mathrm{NaCl}$ conditions $(28,29)$. Our own study does not preclude the possibility that the loss of immunosuppressive functions might be induced by $\mathrm{NaCl}$ in ex vivoisolated Tregs. We observed that $\mathrm{NaCl}$ acted consistently across all investigated $\mathrm{T}$ cell subsets by increasing the coexpression of
FoxP3 with effector cytokines. Although this change in phenotype translated into acquisition of an antiinflammatory Th17 cell fate according to our findings, it might instead result in loss of suppressive functions selectively in Tregs, and in particular in the pTreg subset, which would be in line with previous reports (28-30).

The upregulation of antiinflammatory TGF- $\beta$ expression in human Th17 cells observed in this study is consistent with the previously reported regulation of TGF- $\beta$ production by $\mathrm{NaCl}-$ inducible NFAT5 and the induction of TGF- $\beta$ expression upon hypertonic stress in other cell types (52-54). TGF- $\beta$ has also been identified as an inducer of SGK1 (23). This finding indicates the existence of an autocrine feedback loop that might reinforce the antiinflammatory $\mathrm{T}$ cell fate in hypersaline tissue microenvironments (50). The reduced FoxP3 expression that we observed upon restimulation of Th17 cells in the presence of TGF- $\beta$-neutralizing Abs further suggested a supporting role of $\mathrm{NaCl}$-induced TGF- $\beta$ for the antiinflammatory fate of human Th17 cells. Additionally, SGK1 promotes TGF- $\beta$ signaling through degradation of NEDD$4 \mathrm{~L}$, a molecule that has been reported to limit SMAD2/SMAD3 signaling (55). This suggests that $\mathrm{NaCl}$ not only increases the production of TGF- $\beta$ but also its downstream signaling in target cells, thus mediating an overall immunosuppressive cellular crosstalk.

An intriguing finding of our study was that proinflammatory cytokines such as IL-1 $\beta$ can license $\mathrm{NaCl}$ for $\mathrm{T}$ cell pathogenicity and thus serve as switch factors for the divergent functional effects of $\mathrm{NaCl}$ on human Th17 cells. $\mathrm{NaCl}$ either amplified antiinflammatory human Th17 cell properties or maintained proinflammatory properties, depending on this cytokine switch. Our observation might 
A
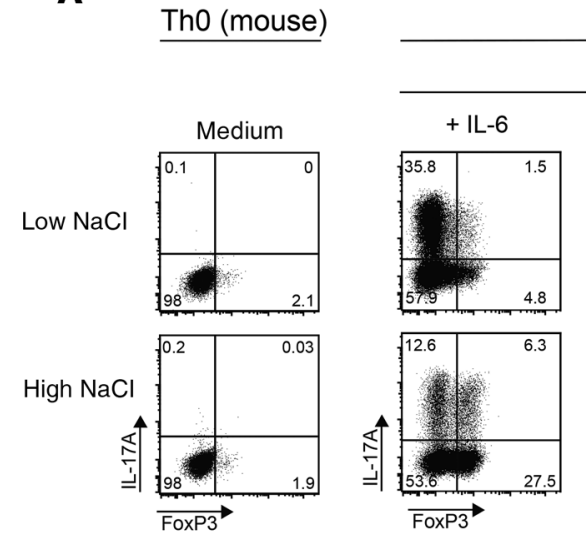

Th17 (mouse)

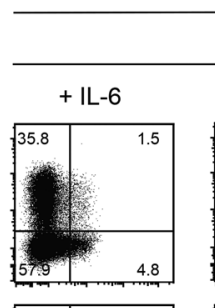

with TGF- $\beta$
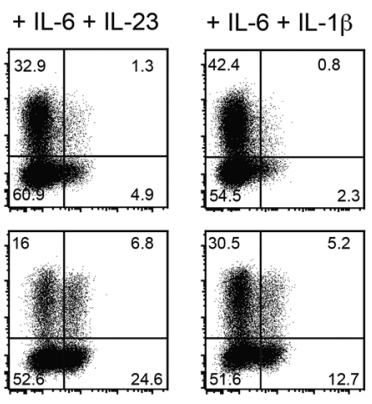

B
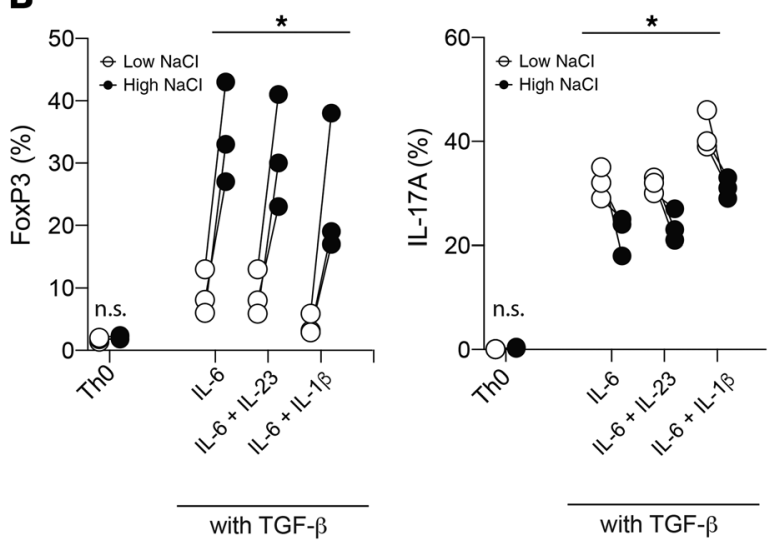

C

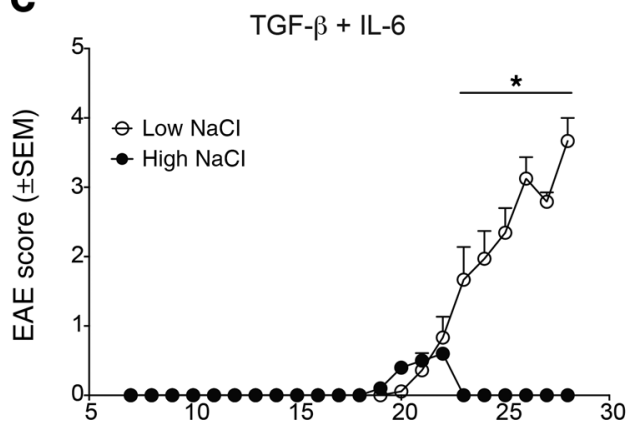

Time (Days after transfer)
D

Th17 (mouse)
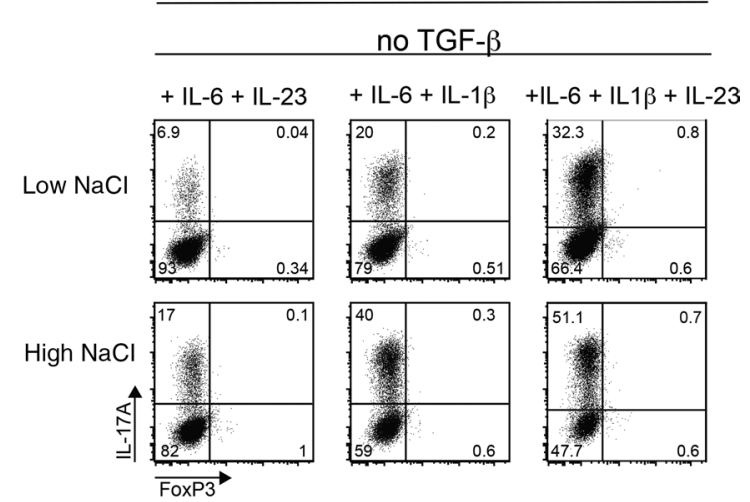

E
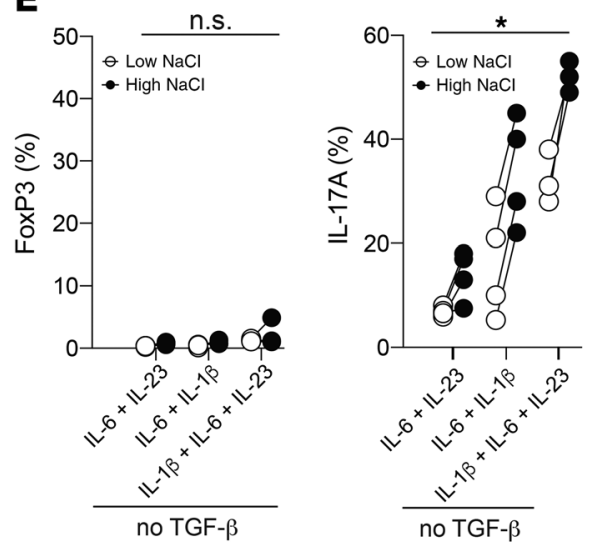

$\mathbf{F}$

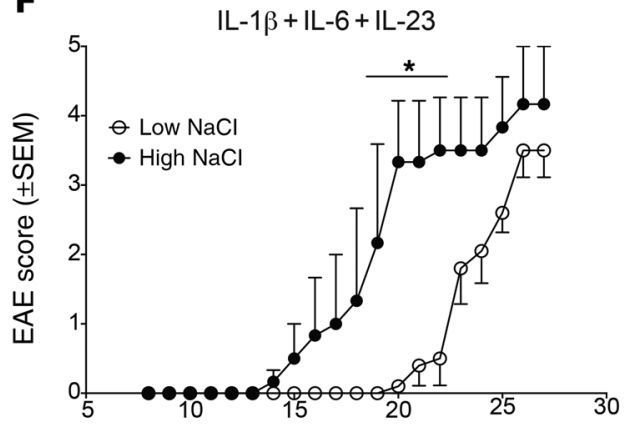

Time (Days after transfer)

Figure 7. TGF- $\beta$ governs the reciprocal enhancement of pro- versus antiinflammatory Th17 cell functions by NaCl in vitro and in vivo in an EAE mouse model. (A) Naive murine CD4+ $\mathrm{T}$ cells from $2 \mathrm{D} 2$ mice were cultured in vitro in neutral (Th0) or various Th17-polarizing conditions (Th17), including TGF- $\beta$ in low- or high-NaCl conditions, and analyzed by FACS on day 3.5 for IL-17A and FoxP3 expression. Representative dot plots show intracellular IL-17A and FoxP3 expression after restimulation of the cells with PMA and ionomycin. (B) Intracellular IL-17A and FoxP3 expression was quantified as in A. (C) Clinical EAE scores $(0-5)$ were determined after adoptive transfer of T cells $\left(1.5 \times 10^{6}\right)$ that were polarized in vitro for 3.5 days with TCF- $\beta$ and IL- 6 (both $25 \mathrm{ng} / \mathrm{mL}$ ) in highor low- $\mathrm{NaCl}$ conditions. ( $\mathbf{D}$ and $\mathbf{E}$ ) Naive murine $\mathrm{CD} 4^{+} \mathrm{T}$ cells were cultured as in $\mathbf{A}$ in the absence of exogenous TGF- $\beta$. Representative dot plots and summary plots are shown. (F) Clinical EAE scores after adoptive transfer of T cells $\left(2 \times 10^{6}\right)$ that were polarized in vitro for 3.5 days with IL-1 3 , IL-6, and IL-23 in highversus low-NaCl conditions. ${ }^{*} P<0.05$, A 2-tailed, paired Student's $t$ test was performed for pairwise comparisons of low- and high-NaCl conditions ( $n=3-4$ mice; data are representative of at least 3 independent experiments) (B and $\mathbf{E}$ ) and 2-way ANOVA with Bonferroni's multiple comparisons test (C and $\mathbf{F}$ ).

explain why the direct antiinflammatory property of $\mathrm{NaCl}$ has previously been masked and therefore overlooked in priming experiments involving polarizing cytokines, which dominantly inhibit FoxP3 expression (22). We showed that these cytokines were also sufficient to obscure the direct effect of $\mathrm{NaCl}$ on IL-17A upregulation in effector Th17 cells, as no synergistic effects were observed (22). Proinflammatory Th17-polarizing cytokines also downregulated autocrine TGF- $\beta$ production, thus abrogating the positive autocrine feedback for FoxP3 upregulation in human Th17 cells that was promoted by high- $\mathrm{NaCl}$ conditions (see model in Supplemental Figure 8). Cumulatively, these findings highlight how changing 1 factor of the microenvironment can shift the overall immune response in the opposite direction. Cytokine-blocking therapies might therefore amplify the antiinflammatory effects of $\mathrm{NaCl}$ in the inflamed tissue. 
Our findings with murine $\mathrm{T}$ cells also challenge the current concept that $\mathrm{NaCl}$ promotes $\mathrm{Th} 17$ cell pathogenicity and thus autoimmunity. Previous studies in mice have indicated that $\mathrm{NaCl}$ has a pathogenic impact on murine Th17 cell differentiation, but they did not address FoxP3 coexpression by these cells, which is well known to alter the functionality of differentiating Th17 cells $(8,45)$. In addition, naive $\mathrm{T}$ cell polarization requires cytokine signaling, thus obscuring direct $\mathrm{NaCl}$ effects. Here, we found that TGF- $\beta$ acted as a critical molecular switch factor that amplified the antiinflammatory effects of $\mathrm{NaCl}$, i.e., FoxP3 upregulation and IL-17A downregulation, whereas its absence allowed for amplification of the proinflammatory murine Th17 cell phenotype by $\mathrm{NaCl}$. Consistent with our findings, results from other studies have shown that $\mathrm{NaCl}$ has little effect on murine IL-17A production in TGF- $\beta$-plus-IL-6-polarizing conditions and that there is no role for SGK1 expression in this process (23). Instead, an important role for SGK1-dependent murine IL-17A upregulation was previously observed in IL-23-containing priming conditions (23), highlighting the pathogenic role of $\mathrm{NaCl}$ in the context of proinflammatory cytokines. Exogenous TGF- $\beta$ was critical for allowing $\mathrm{NaCl}$ to enhance the antiinflammatory murine Th17 cell fate, possibly due to insufficient autocrine TGF- $\beta$ production in the presence of polarizing proinflammatory cytokines. This was comparable to our human $\mathrm{T}$ cell cultures, in which differential levels of autocrine TGF- $\beta$ that were secondarily modulated by polarizing cytokines likewise translated into divergent Th17 cell effector functions in high- $\mathrm{NaCl}$ conditions (see model in Supplemental Figure 8). This observation is reminiscent of the reciprocal regulation by the IL- 6 switch factor that has previously been reported for murine Tregs and Th17 cells in TGF- $\beta$ conditions $(40,46)$. The detailed molecular mechanism by which these divergent Th17 cell fates are regulated in the context of ionic signaling remains to be dissected.

To demonstrate that these $\mathrm{NaCl}$-induced $\mathrm{T}$ cell cytokine expression profiles translate into either pro- or antiinflammatory $\mathrm{T}$ cell effector functions, we validated them in vivo. Previously, a pathogenic effect of $\mathrm{NaCl}$ has been emphasized for autoimmune diseases in mouse models, which had been based on disease aggravation following a high- $\mathrm{NaCl}$ diet $(18,22,23,56-58)$. Indirect effects, such as modification of the gut microbiota or increased blood-brain barrier permeability, most likely account for this overall dietary effect (15, $43,59)$. Using the adoptive transfer mouse model of EAE, we were able to circumvent the widespread effects of diet on the immune system and beyond. This model revealed that $\mathrm{NaCl}$ exerted direct as opposed to indirect antiinflammatory $\mathrm{T}$ cell functions in vivo, which were accompanied by lower disease activity. Our findings were consistent with a $\mathrm{NaCl}$-induced enrichment of $\mathrm{FoxP}^{+}$versus IL-17A ${ }^{+}$ $\mathrm{T}$ cells in the CNS. The opposite disease outcome was amplified by $\mathrm{NaCl}$, however, when murine Th17 cells were primed in the absence of exogenous TGF- $\beta$, consistent with our in vitro Th17 cell phenotyping data. Cumulatively, our findings challenge the current concept that $\mathrm{NaCl}$ promotes autoimmune disease pathogenicity per se. Instead, they propose a dual context-dependent function of $\mathrm{NaCl}$ with reciprocal regulation of autoimmunity.

Strikingly, our adoptive $\mathrm{T}$ cell transfer strategy also suggested in vivo stability of the protective Th17 cell fate that was induced in high- $\mathrm{NaCl}$ conditions in vitro. This is illustrated by the maintenance of the antiinflammatory FoxP3 ${ }^{\text {hi }}$ IL- $17 \mathrm{~A}^{\text {lo }}$ phenotype of CNS-infiltrating $\mathrm{T}$ cells in the EAE mouse model, which corresponded to their in vitro-generated phenotype and correlated with reduced disease scores. These findings were also in line with the maintenance of NaCl-induced FoxP3 upregulation in human Th17 cells upon repeated restimulations in changing microenvironments. Cumulatively, this in vivo stability of in vitro-induced $\mathrm{T}$ cell effects has implications for $\mathrm{NaCl}$ in adoptive $\mathrm{T}$ cell therapies in settings of autoimmunity, cancer, and infections.

$\mathrm{NaCl}$ has previously been reported to accumulate in bacterial skin infections and to play antimicrobial roles via macrophages (60). Our data demonstrate that $\mathrm{NaCl}$ exerts differential effects on human Th17 cells depending on their microbial antigen specificities. $\mathrm{NaCl}$ induced strong FoxP3 upregulation in S. aureus-specific Th17 cells but not $C$. albicans-specific Th17 cells. This intriguing pathogen-specific effect of $\mathrm{NaCl}$ is consistent with the differential Th17 priming requirements for IL-1 $\beta$ for $C$. albicans- versus $S$. aureusspecific $\mathrm{T}$ cells that we have previously reported (2). Accordingly, C. albicans-specific $\mathrm{T}$ cell priming in the presence of IL-1 $\beta$-blocking Abs enhanced the ability of $\mathrm{NaCl}$ to upregulate FoxP3 expression compared with culture conditions in the absence of $\mathrm{NaCl}$. Together, the data suggest differential effects of $\mathrm{NaCl}$ on Th17 cells depending on the type of infection. Moreover, they demonstrate that the dichotomous effects of $\mathrm{NaCl}$ are not dependent on the simultaneous presence of the IL- $1 \beta$ switch, but rather are associated with prior IL-1 $\beta$ signaling experience during the initial pathogen-specific Th17 cell-priming phase. Whether this durable T cell experience is imprinted epigenetically remains to be investigated. These findings highlight that $\mathrm{NaCl}$ fine-tunes antimicrobial immune responses as a rheostat depending on cytokine experience and the type of pathogen. It remains to be determined in the context of specific tissues and infections whether $\mathrm{NaCl}$ is beneficial for microbial clearance by the adaptive $\mathrm{T}$ cell immune system.

Our findings suggest that the enrichment of $\mathrm{NaCl}$ in peripheral tissues could stabilize immunotolerance in steady-state conditions or, alternatively, promote inflammation in settings of infections or autoimmunity. These insights could translate into new therapeutic strategies, since currently available drugs that block IL-1 $\beta$, IL-6, or IL-23 in chronic inflammatory diseases might shift the balance toward beneficial clinical outcomes upon $\mathrm{NaCl}$ accumulation in peripheral tissues.

\section{Methods}

Cell purification and sorting. Fresh peripheral blood was obtained from healthy donors. PBMCs were isolated by density gradient centrifugation using Ficoll-Paque Plus (GE Healthcare). Th cells and monocytes were isolated from the PBMCs by positive selection with CD4- or CD14-specific microbeads (Miltenyi Biotec), respectively, using an autoMACS Pro Separator. Th cell subsets were sorted to at least $98 \%$ purity using the following markers: Th1 subset, CXCR3+CCR4-CCR6 ${ }^{-}$ CD45RA; Th2 subset, CXCR3-CCR4 ${ }^{+}{ }^{-}{ }^{-}{ }^{-}{ }^{-}{ }^{-C D} 45 R^{-}$; and Th17 subset, CXCR3 ${ }^{-} \mathrm{CCR} 4^{+} \mathrm{CCR}{ }^{+}{ }^{+} \mathrm{CD} 45 \mathrm{RA}^{-}$. Memory Th cells were isolated as CD45RA- lymphocytes, and naive T cells were isolated as CD45RA ${ }^{+}$ $\mathrm{CD}^{2} 5 \mathrm{RO}^{-} \mathrm{CCR}^{+}$lymphocytes at a purity of over $98 \%$. The Abs used for sorting by flow cytometry were identical to those we have described previously $(2,6)$. The cells were sorted with a BD FACSAria III (BD Biosciences). Skin $\mathrm{T}$ cells were isolated from fresh human abdominal skin 
samples obtained after plastic surgery by overnight collagenase digestion (Collagenase Type IV, Thermo Fisher Scientific) and cell sorting.

Cell culture. Human T cells were cultured in RPMI 1640 medium supplemented with $2 \mathrm{mM}$ glutamine, $1 \%$ (vol/vol) nonessential amino acids, $1 \%$ (vol/vol) sodium pyruvate, penicillin $(50 \mathrm{U} / \mathrm{mL})$, streptomycin $(50 \mu \mathrm{g} / \mathrm{mL}$; all from Invitrogen, Thermo Fisher Scientific), and 10\% (vol/vol) FCS (Biochrom). Hypersalinity (high $\mathrm{NaCl}$ levels) was induced by increasing the $\mathrm{NaCl}$ concentration to $185 \mathrm{mM}$, whereas the baseline concentrations of $\mathrm{NaCl}$ in cell culture medium including supplements were $140 \mathrm{mM}$ ( $\mathrm{NaCl}$, MilliporeSigma). Final sodium concentrations were confirmed in the cell culture media by potentiometry with a Cobas 8000 Analyzer (Roche). In the indicated experiments, $\mathrm{T}$ cell cultures were performed in the presence of recombinant cytokines (IL-6, $50 \mathrm{ng} / \mathrm{mL}$; TGF- $\beta, 5 \mathrm{ng} / \mathrm{mL}$; IL-1 $\beta, 10$ $\mathrm{ng} / \mathrm{mL}$; IL-23, $50 \mathrm{ng} / \mathrm{mL}$; IL-21, $50 \mathrm{ng} / \mathrm{mL}$; all from R\&D Systems) or neutralizing Abs (anti-IL-1 $\beta$, BD Biosciences; anti-TGF- $\beta$, R\&D Systems; both $10 \mu \mathrm{g} / \mathrm{mL}$ ). T cells were stimulated with plate-bound anti-CD3 $(2 \mu \mathrm{g} / \mathrm{mL}$, clone TR66) and anti-CD28 (2 $\mu \mathrm{g} / \mathrm{mL}$ CD28.2; both from BD Biosciences) Abs. T cell clones were generated in nonpolarizing conditions, as described previously, following single-cell deposition via flow cytometry-assisted cell sorting or by limiting dilution plating (61). Pathogen-specific T cell clones were generated as described previously $(2,42)$.

Cytokine and transcription factor analyses. For intracellular cytokine staining, human cells were restimulated for 5 hours with PMA and ionomycin, with brefeldin A added for the final 2.5 hours of culture (all from MilliporeSigma). The cells were fixed and permeabilized with Cytofix/Cytoperm (BD Biosciences) according to the manufacturer's instructions. For transcription factor analysis, cells were fixed and permeabilized with Cytofix/Cytoperm (eBioscience). The cells were stained with anti-cytokine Abs (Abs specific for IL-17A [clone BL168], IFN- $\gamma$ [4S.B3], IL-22 [clone 2G12A41], and TGF- $\beta$ [TW42F8]; all from BioLegend) and with Abs against transcription factors (ROR- $\gamma$ t [clone AFKJS-9]), FoxP3 [clone PCH101], both eBioscience) and were analyzed with a BD LSRFortessa (BD Biosciences), a CytoFLEX (Beckman Coulter), or a MACSQuant Analyzer (Miltenyi Biotec). Flow cytometric data were analyzed with FlowJo (Tree Star) or Cytobank (Cytobank Inc.) software. Cytokines in culture supernatants were quantified by ELISA (R\&D Systems) or by Luminex (Thermo Fisher Scientific), according to standard protocols, after restimulation of cultured T cells with phorbol 12-13-dibutyrate (50 nM, MilliporeSigma) and plate-bound anti-CD3 $(1 \mu \mathrm{g} / \mathrm{mL}$, TR66) for 8 hours or as indicated in the respective figure legends.

For experiments with murine $\mathrm{T}$ cells, single-cell suspensions were generated from the spleen and inguinal, axial, and brachial lymph nodes of C57BL/6 mice (Janvier Labs). Naive CD4 ${ }^{+} \mathrm{T}$ cells were obtained by negative selection using a mouse naive $\mathrm{CD}^{+}$ $\mathrm{T}$ Cell Isolation Kit (StemCell Technologies or Miltenyi Biotec). The cells were seeded at a density of 200,000 cells/well in a 96-well flat-bottomed plate and stimulated with plate-bound anti-CD3 and anti-CD28 Abs $(2 \mu \mathrm{g} / \mathrm{mL}$ anti-CD3 [clone 145-2C11] and $2 \mu \mathrm{g} / \mathrm{mL}$ anti-CD28 [clone 37.51] for in vitro experiments; $4 \mu \mathrm{g} / \mathrm{mL}$ anti-CD3 and soluble anti-CD28 for in vivo experiments; Bio X Cell) and different mixtures of cytokines and mAbs (ThO conditions: anti-IL-4, antiIFN- $\gamma$; Th17 conditions: anti-IL-4, anti-IFN- $\gamma$, and cytokine mixtures as indicated) with or without the addition of $40 \mathrm{mM} \mathrm{NaCl}$ in DMEM (supplemented with $10 \%$ FCS, 10 mM HEPES, 1 mM sodium pyruvate,
$1 \times$ nonessential amino acids [MEM NEAA], $50 \mu \mathrm{M} \beta$-mercaptoethanol, and $100 \mathrm{U}$ penicillin-streptomycin; Life Technologies, Thermo Fisher Scientific). Neutralizing Abs and cytokines were used at the following concentrations: anti-IL-4 (clone 11B11, $10 \mu \mathrm{g} / \mathrm{mL}$ ), anti-IFN- $\gamma$ (clone XMG1.2, $10 \mu \mathrm{g} / \mathrm{mL}$ ) from BioLegend, and anti-TGF- $\beta$ (clone 1D11.16.8, $20 \mu \mathrm{g} / \mathrm{mL})$ from Bio X Cell; and IL-6 (25 ng/mL), IL-1 $\beta$ (20 ng/mL), IL-23 (20 ng/mL), and TGF- $\beta$ (2 ng/mL) from PeproTech or R\&D Systems. After 2.5 days in culture, cells were split into 2 new 96-well plates with a freshly prepared cytokine mixture. After 3.5 days in culture, cells were stimulated with $10 \mathrm{nM}$ PMA and $1 \mu \mathrm{M}$ ionomycin for 2 hours, followed by the addition of $5 \mu \mathrm{g} / \mathrm{mL}$ brefeldin A for another 2 hours. Dead cells were excluded with Fixable Viability Dye eFluor 780 (eBioscience) or LIVE/DEAD Fixable NiR Dead Cell Stain (Invitrogen, Thermo Fisher Scientific). Nonspecific binding was blocked with anti-CD16/anti-CD32 (clone 93, BioLegend) plus 2\% normal mouse serum and $2 \%$ normal rat serum. Detection of intracellular FoxP3 (FJK-16s) and IL-17A (TC11-18H10.1) was performed using the FoxP3/Transcription Factor Staining Buffer Set (eBioscience) according to the manufacturer's instructions. Data were acquired on an $\mathrm{BD}$ LSRFortessa (BD Biosciences), a BD FACSCanto II (BD Biosciences), or a Cytoflex (Beckman Coulter) and analyzed with FlowJo software (Tree Star). Mice were housed in specific pathogen-free conditions. All data for C57BL/6 mice were reproduced with 2D2 [C57BL/6-Tg (Tcra2D2,Tcrb2D2)1Kuch/J] transgenic mice (The Jackson Laboratory).

Adoptive transfer EAE mouse model. Single-cell suspensions were generated from spleen, inguinal, axial, brachial, and mandibular lymph nodes of 2D2_Foxp3.gfp donor mice [Tg(Tcra2D2, Tcrb2D2)1Kuch crossed with Treg reporter strain Foxp3 $3^{\text {tm1Kuch }}$ on a C57BL/6 background] by passing the tissue through a $70-\mu \mathrm{m}$ cell strainer. Naive $\mathrm{CD} 4^{+} \mathrm{T}$ cells were obtained by pre-enrichment using an "untouched" CD4 $4^{+} \mathrm{T}$ Cell Isolation Kit (Miltenyi Biotec) with subsequent flow cytometric analysis (CD4 ${ }^{+}$[clone RM4-5], CD44 $4^{\text {lo }}$ [clone IM7], Foxp3.gfp ${ }^{-}$. Cells were seeded at a density of 200,000 cells/ well in a flat-bottom 96-well plate and stimulated with plate-bound anti-CD3 (clone 145-2C11, $4 \mu \mathrm{g} / \mathrm{mL}$, Bio X Cell) and soluble antiCD28 (clone PV-1, $2 \mu \mathrm{g} / \mathrm{mL}$, Bio X Cell). Recombinant cytokines (all from R\&D Systems) and mAbs (anti-IFN- $\gamma$ and anti-IL-4 [both $10 \mu \mathrm{g} /$ $\mathrm{mL}$ ], from Bio X Cell plus $25 \mathrm{ng} / \mathrm{mL}$ IL- 6 and $2 \mathrm{ng} / \mathrm{mL}$ TGF- $\beta 1$ or IL-1 $\beta$, IL-6, IL-23 [all $25 \mathrm{ng} / \mathrm{mL}$ ], respectively) were added to DMEM (supplemented with $10 \%$ FCS, $50 \mu \mathrm{M} \beta$-mercaptoethanol, MEM-NEAA, MEM vitamins, folic acid, $50 \mathrm{U} / \mathrm{mL}$ penicillin, $50 \mu \mathrm{g} / \mathrm{mL}$ streptomycin, and $0.1 \mathrm{mg} / \mathrm{mL}$ gentamicin) with or without addition of $40 \mathrm{mM}$ $\mathrm{NaCl}$. Cells were cultured for 3.5 days before adoptive transfer. Differentiated T cells were injected i.v. into Rag1-deficient recipient mice (Rag1 ${ }^{\text {tm1Mom}}$ ) that received 200 ng PTx (MilliporeSigma) i.v. on the day of and 2 days after transfer. Clinical signs of EAE were assessed daily with the following scoring system: 0 , no signs of disease; 1 , loss of tone in the tail; 2, hind limb paresis; 3, hind limb paralysis; 4, tetraplegia; and 5 , moribund. At the peak of disease (29 days), CNS-infiltrating cells were isolated after perfusion through the left cardiac ventricle with PBS. Brain and spinal cord were dissected and digested with collagenase D $(2.5 \mathrm{mg} / \mathrm{mL})$ and DNase I $(1 \mathrm{mg} / \mathrm{mL})$ at $37^{\circ} \mathrm{C}$ for $45 \mathrm{~min}$ utes. After passing the tissue through a $70-\mu \mathrm{m}$ cell strainer, cells were separated by discontinuous Percoll gradient (70\%/37\%) centrifugation. Mononuclear cells were isolated from the interphase.

Gene expression analysis. Total RNA was extracted using TRIzol Reagent (Invitrogen, Thermo Fisher Scientific) according to the 
manufacturer's instructions. A high-capacity cDNA Reverse Transcription Kit (Applied Biosystems) was used for cDNA synthesis according to the manufacturer's protocol. Transcripts were quantified by real-time PCR with predesigned TaqMan Gene Expression Assays (SGK1, Hs00985033; NFAT5, Hs00232437; RORC2, Hs01076112; FOXP3, Hs01085834; IL10, Hs00961622; CTLA4, Hs00175480_m1; 18S, Hs03928985; LAG3, Hs00958444_g1; and ICOS, Hs00359999_ $\mathrm{m} 1$ ) and reagents (Applied Biosystems). mRNA abundance was normalized to the amount of $18 \mathrm{~S}$ rRNA and is expressed in AU.

For RNA-Seq analyses, Th17 cells were isolated ex vivo as described above and stimulated for 48 hours with CD3 and CD28 $\mathrm{mAbs}$ for a total culture duration of 5 days in the presence of low and high $\mathrm{NaCl}$ concentrations. Total RNA was extracted from cells lysed in TRI Reagent (MilliporeSigma) according to the manufacturer's protocol. RNA was quantified using a NanoDrop 2000 spectrophotometer (Thermo Fisher Scientific), and its quality was verified with an Agilent 2100 Bioanalyzer (Agilent Technologies) according to the manufacturer's guidelines.

Library preparation for RNA-Seq was performed using the TruSeq Stranded Total RNA Sample Preparation Guide (Illumina) starting with $450 \mathrm{ng}$ RNA as the input for each sample. Only 11 cycles were used for PCR amplification to minimize PCR bias. The barcoded libraries were sequenced on a HiSeq 2500 (Illumina) with paired-end, 100-bp reads. Approximately $6 \mathrm{~Gb}$ of sequencing reads were produced on average per sample. The reads were mapped to the reference transcriptome built from the human genome assembly hg38 (GRCh38) using STAR, version 2.6.1a (62). Transcripts were quantified with Salmon, version 0.11.3, in the alignment-based mode (63). Downstream analyses were performed with the statistical framework R (ISBN 3-900051-07-0). Differentially expressed genes were identified using the R package DESeq2 (64), taking into consideration the effect of samples. No fold-change cutoff was set for determining differentially expressed genes, thus, all genes with a FDR of less than 0.05 by the Wald test were considered significantly dysregulated. Plots were produced with the $\mathrm{R}$ package ggplot2 (65). The clusterProfiler R package (66) was used for GSEA, and genes were ranked according to the shrunken foldchange values calculated by DESeq2, as previously suggested (64). Our raw data are publicly available in the NCBI's Gene Expression Omnibus database (GEO GSE148669).

Lentivirus-mediated gene silencing. Bacterial stocks containing lentiviral vectors with shRNAs targeting SGK1 and NFAT5 were purchased from MilliporeSigma (SGK1: TRCNO000196562, TRCNO000194957, TRCNO000040175, TRCNO000040177, TRCN0000010432; NFAT5: TRCNO000437810, TRCNO000020021, TRCNO000020022, TRCN0000020023, and TRCN0000020019). All vectors were amplified and purified using a MaxiPrep or MidiPrep Kit (QIAGEN) according to the manufacturer's instructions. Lentiviral particles were generated in HEK293 cells. Presorted human memory T cells $\left(5 \times 10^{4}\right)$ were activated on anti-CD3/anti-CD28 Ab-coated plates for 12 hours before transduction with the supernatants from cultures with pooled lentiviral particles against $S G K 1$ or NFAT5 or those without shRNA insertion.
After 48 hours, the cells were washed and selected with puromycin (MilliporeSigma). Silenced gene expression was verified by qRT-PCR 4 days after transduction.

Statistics. The statistical tests are indicated in the respective figure legends. Error bars indicate the SEM. $P$ values of 0.05 or less were considered significant. Analyses were performed using GraphPad Prism 7-8 (GraphPad Software).

Study approval. Ethics approval was obtained from the IRB of the Technical University of Munich (195/15s, 146/17s, 491/16s) and the Charité - Universitätsmedizin Berlin (EA1/221/11). Participants of this study provided written informed consent. All work involving humans was carried out in accordance with Declaration of Helsinki principles for experiments involving humans. All experiments were performed in accordance with the regulations of the Regierung von Oberbayern and the Regierungspräsidium Giessen.

\section{Author contributions}

JM performed experiments with human material and analyzed and interpreted the data. JZ and AK performed murine in vitro experiments and, together with $\mathrm{DB}$ and $\mathrm{AP}$, analyzed and interpreted the data. YYC and DS performed experiments with human T cells and analyzed and interpreted the data. EG performed mRNA-Seq. GPDA performed bioinformatic and statistical analyses. IDJ and TR generated and characterized the antigen lysates of C. albicans yeast and $S$. aureus, respectively. SH and FP performed experiments related to the transfer EAE model in 2 independent mouse facilities and, together with TK and $\mathrm{MH}$, analyzed and interpreted the data. SF and JH performed experiments and analyzed data related to the stability of Th17 cell functions in response to $\mathrm{NaCl}$. CEZ conceived the study, supervised the experiments, interpreted the data, and wrote the manuscript.

\section{Acknowledgments}

This work was supported by the Deutsche Forschungsgemeinschaft (DFG, German Research Foundation, SFB1054) (Projektnummer: 210592381) Teilprojekt B10 (to CEZ), B12 (to DB), B06 (to TK); SFB1335 (Projektnummer: 360372040), Teilprojekt P18 (to CEZ); the Emmy Noether Program BA 5132/1-1 and BA 5132/12 (252623821) (to DB) and PE 2681/1-1 (to AP); DFG HU 1824/51, HU 1824/7-1, GIF I-1474-414.13/2018 (to MH); the Fresenius Stiftung, 2015_A232 (to MH); the Fritz-Thyssen Stiftung (to CEZ); Collaborative Research Center/Transregio 124 Project C5 (to IDJ); and the German Center for Infection Research (to CEZ). TK is supported by Synergy (EXC 2145, ID 390857198). We thank Rebecca Noster and Hanna Meinl for experimental support. We acknowledge the BMC Core Facility Flow Cytometry of the LMU Munich for providing equipment.

Address correspondence to: Christina E. Zielinski, TranslaTUM and Institute of Virology, Technical University of Munich, Ismaninger Strasse 22, Bau 522, D-81675 Munich, Germany. Phone: 49.89.4140.7143; Email: christina.zielinski@tum.de.
1. Zielinski CE, Corti D, Mele F, Pinto D, Lanzavecchia A, Sallusto F. Dissecting the human immunologic memory for pathogens. Immunol Rev. 2011;240(1):40-51.
2. Zielinski CE, et al. Pathogen-induced human TH17 cells produce IFN- $\gamma$ or IL-10 and are regulated by IL-1 $\beta$. Nature. 2012;484(7395):514-518.

3. Patel DD, Kuchroo VK. Th17 cell pathway in human immunity: lessons from genetics and therapeutic interventions. Immunity. 2015;43(6):1040-1051.

4. Sallusto F, Zielinski CE, Lanzavecchia A. Human 
Th17 subsets. Eur JImmunol. 2012;42(9):2215-2220.

5. Stockinger B, Omenetti S. The dichotomous nature of T helper 17 cells. Nat Rev Immunol. 2017;17(9):535-544.

6. Noster R, de Koning HD, Maier E, Prelog M, Lainka E, Zielinski CE. Dysregulation of proinflammatory versus anti-inflammatory human $\mathrm{T}_{\mathrm{H}} 17$ cell functionalities in the autoinflammatory Schnitzler syndrome. J Allergy Clin Immunol. 2016;138(4):1161-1169.e6.

7. Aschenbrenner D, et al. An immunoregulatory and tissue-residency program modulated by c-MAF in human $\mathrm{T}_{\mathrm{H}} 17$ cells. Nat Immunol. 2018;19(10):1126-1136.

8. Ohnmacht C, et al. Mucosal immunology. The microbiota regulates type 2 immunity through ROR $\gamma t^{+}$T cells. Science. 2015;349(6251):989-993.

9. Yang BH, et al. Foxp3(+) T cells expressing ROR $\gamma \mathrm{t}$ represent a stable regulatory T-cell effector lineage with enhanced suppressive capacity during intestinal inflammation. Mucosal Immunol. 2016;9(2):444-457.

10. Lochner $\mathrm{M}$, et al. In vivo equilibrium of proinflammatory $\mathrm{IL}-17+$ and regulatory $\mathrm{IL}-10^{+}$ Foxp $3^{+}$RORgamma $\mathrm{t}^{+} \mathrm{T}$ cells. J Exp Med. 2008;205(6):1381-1393.

11. Langrish CL, et al. IL-23 drives a pathogenic $\mathrm{T}$ cell population that induces autoimmune inflammation. J Exp Med. 2005;201(2):233-240.

12. Gagliani N, et al. Th17 cells transdifferentiate into regulatory $\mathrm{T}$ cells during resolution of inflammation. Nature. 2015;523(7559):221-225.

13. Lee $Y$, et al. Induction and molecular signature of pathogenic TH17 cells. Nat Immunol. 2012;13(10):991-999.

14. McGeachy MJ, et al. TGF-beta and IL-6 drive the production of IL-17 and IL-10 by T cells and restrain $\mathrm{T}(\mathrm{H})-17$ cell-mediated pathology. Nat Immunol. 2007;8(12):1390-1397.

15. Sharif K, Amital H, Shoenfeld Y. The role of dietary sodium in autoimmune diseases: The salty truth. Autoimmun Rev. 2018;17(11):1069-1073.

16. Matthias J, et al. Sodium chloride is an ionic checkpoint for human $\mathrm{T}_{\mathrm{H}} 2$ cells and shapes the atopic skin microenvironment. Sci Transl Med. 2019;11(480):eaau0683.

17. Müller DN, Wilck N, Haase S, Kleinewietfeld M, Linker RA. Sodium in the microenvironment regulates immune responses and tissue homeostasis. Nat Rev Immunol. 2019;19(4):243-254.

18. Luo $\mathrm{T}$, et al. Th17/Treg imbalance induced by dietary salt variation indicates inflammation of target organs in humans. Sci Rep. 2016;6:26767.

19. Go WY, Liu X, Roti MA, Liu F, Ho SN. NFAT5/ TonEBP mutant mice define osmotic stress as a critical feature of the lymphoid microenvironment. Proc Natl Acad Sci USA. 2004;101(29):10673-10678.

20. Hofmeister LH, Perisic S, Titze J. Tissue sodium storage: evidence for kidney-like extrarenal countercurrent systems? Pflugers Arch. 2015;467(3):551-558.

21. Fischereder M, et al. Sodium storage in human tissues is mediated by glycosaminoglycan expression. Am J Physiol Renal Physiol. 2017;313(2):F319-F325.

22. Kleinewietfeld $\mathrm{M}$, et al. Sodium chloride drives autoimmune disease by the induction of pathogenic
TH17 cells. Nature. 2013;496(7446):518-522.

23. Wu C, et al. Induction of pathogenic TH17 cells by inducible salt-sensing kinase SGK1. Nature. 2013;496(7446):513-517.

24. Sallusto F, Lenig D, Förster R, Lipp M, Lanzavecchia A. Two subsets of memory $\mathrm{T}$ lymphocytes with distinct homing potentials and effector functions. Nature. 1999;401(6754):708-712.

25. Zielinski CE. Human T cell immune surveillance: phenotypic, functional and migratory heterogeneity for tailored immune responses. Immunol Lett. 2017;190:125-129.

26. Thome JJ, Farber DL. Emerging concepts in tissue-resident $\mathrm{T}$ cells: lessons from humans. Trends Immunol. 2015;36(7):428-435.

27. Park CO, Kupper TS. The emerging role of resident memory $\mathrm{T}$ cells in protective immunity and inflammatory disease. Nat Med.2015;21(7):688-697.

28. Hernandez AL, et al. Sodium chloride inhibits the suppressive function of $\mathrm{FOXP}^{+}$regulatory T cells. J Clin Invest. 2015;125(11):4212-4222.

29. Luo Y, et al. Negligible effect of sodium chloride on the development and function of TGF- $\beta$ induced $\mathrm{CD} 4^{+}$Foxp $3^{+}$regulatory T cells. Cell Rep 2019;26(7):1869-1879.e3.

30. Beriou G, et al. IL-17-producing human peripheral regulatory $\mathrm{T}$ cells retain suppressive function. Blood. 2009;113(18):4240-4249.

31. Wang J, Ioan-Facsinay A, van der Voort EI, Huizinga TW, Toes RE. Transient expression of FOXP3 in human activated nonregulatory $\mathrm{CD}^{+}$ T cells. Eur J Immunol. 2007;37(1):129-138.

32. Sakaguchi S, Mikami N, Wing JB, Tanaka A, Ichiyama K, Ohkura N. Regulatory T cells and human disease. Annu Rev Immunol. 2020;38:541-566.

33. López-Rodríguez C, Aramburu J, Jin L, Rakeman AS, Michino M, Rao A. Bridging the NFAT and NF-kappaB families: NFAT5 dimerization regulates cytokine gene transcription in response to osmotic stress. Immunity. 2001;15(1):47-58.

34. Lang F, Stournaras C, Alesutan I. Regulation of transport across cell membranes by the serumand glucocorticoid-inducible kinase SGK1. Mol Membr Biol. 2014;31(1):29-36.

35. Yan J, et al. Transcription factor binding in human cells occurs in dense clusters formed around cohesin anchor sites. Cell. 2013;154(4):801-813.

36. Acosta-Rodriguez EV, Napolitani G, Lanzavecchia A, Sallusto F. Interleukins 1beta and 6 but not transforming growth factor-beta are essential for the differentiation of interleukin 17-producing human T helper cells. Nat Immunol. 2007;8(9):942-949.

37. Manel N, Unutmaz D, Littman DR. The differentiation of human $\mathrm{T}(\mathrm{H})-17$ cells requires transforming growth factor-beta and induction of the nuclear receptor RORgammat. Nat Immunol. 2008;9(6):641-649.

38. Ikeda S, Saijo S, Murayama MA, Shimizu K, Akitsu A, Iwakura Y. Excess IL-1 signaling enhances the development of Th17 cells by downregulating TGF- $\beta$-induced Foxp3 expression. J Immunol. 2014;192(4):1449-1458.

39. Izcue A, et al. Interleukin-23 restrains regulatory $\mathrm{T}$ cell activity to drive $\mathrm{T}$ cell-dependent colitis. Immunity. 2008;28(4):559-570.

40. Bettelli E, et al. Reciprocal developmental pathways for the generation of pathogenic effector TH17 and regulatory T cells. Nature. 2006;441(7090):235-238.

41. Acosta-Rodriguez EV, et al. Surface phenotype and antigenic specificity of human interleukin 17-producing Thelper memory cells. Nat Immunol. 2007;8(6):639-646.

42. Braun JM, Zielinski CE. In vitro generation of microbe-specific human Th17 cells. Methods Mol Biol. 2014;1193:97-104.

43. Wilck N, et al. Salt-responsive gut commensal modulates $\mathrm{T}_{\mathrm{H}} 17$ axis and disease. Nature. 2017;551(7682):585-589.

44. Peters A, Lee Y, Kuchroo VK. The many faces of Th17 cells. Curr Opin Immunol. 2011;23(6):702-706.

45. Zhou L, et al. TGF-beta-induced Foxp3 inhibits $\mathrm{T}(\mathrm{H}) 17$ cell differentiation by antagonizing RORgammat function. Nature. 2008;453(7192):236-240.

46. Veldhoen M, Hocking RJ, Atkins CJ, Locksley RM, Stockinger B. TGFbeta in the context of an inflammatory cytokine milieu supports de novo differentiation of IL-17-producing T cells. Immunity. 2006;24(2):179-189.

47. Ghoreschi K, et al. Generation of pathogenic $\mathrm{T}(\mathrm{H}) 17$ cells in the absence of TGF- $\beta$ signalling. Nature. 2010;467(7318):967-971.

48. Müller DN, Wilck N, Haase S, Kleinewietfeld M, Linker RA. Sodium in the microenvironment regulates immune responses and tissue homeostasis. Nat Rev Immunol. 2019;19(4):243-254.

49. Matthias J, Zielinski CE. Shaping the diversity of Th2 cell responses in epithelial tissues and its potential for allergy treatment. Eur J Immunol. 2019;49(9):1321-1333.

50. Wu C, et al. SGK1 governs the reciprocal development of Th17 and regulatory T cells. Cell Rep. 2018;22(3):653-665.

51. Heikamp EB, et al. The AGC kinase SGK1 regulates TH1 and TH2 differentiation downstream of the mTORC2 complex. Nat Immunol. 2014;15(5):457-464.

52. Li W, et al. MiR-568 inhibits the activation and function of $\mathrm{CD} 4^{+} \mathrm{T}$ cells and Treg cells by targeting NFAT5. Int Immunol. 2014;26(5):269-281.

53. Sugiura T, et al. Effects of hypertonic stress on transforming growth factor-beta activity in normal rat kidney cells. Kidney Int. 1998;53(6):1654-1660.

54. Gutcher I, Donkor MK, Ma Q, Rudensky AY, Flavell RA, Li MO. Autocrine transforming growth factor- $\beta 1$ promotes in vivo Th17 cell differentiation. Immunity. 2011;34(3):396-408.

55. Gao S, et al. Ubiquitin ligase Nedd4L targets activated Smad2/3 to limit TGF-beta signaling. Mol Cell. 2009;36(3):457-468.

56. Aguiar SLF, et al. High-salt diet induces IL-17dependent gut inflammation and exacerbates colitis in mice. Front Immunol. 2017;8:1969.

57. Jung SM, et al. Sodium chloride aggravates arthritis via Th17 polarization. Yonsei Med J. 2019;60(1):88-97.

58. Wei Y, et al. High salt diet stimulates gut Th17 response and exacerbates TNBS-induced colitis in mice. Oncotarget. 2017;8(1):70-82.

59. Krementsov DN, Case LK, Hickey WF, Teuscher C. Exacerbation of autoimmune neuroinflammation by dietary sodium is genetically controlled 
and sex specific. FASEB J. 2015;29(8):3446-3457. 60. Jantsch J, et al. Cutaneous $\mathrm{Na}^{+}$storage strengthens the antimicrobial barrier function of the skin and boosts macrophage-driven host defense. Cell Metab. 2015;21(3):493-501.

61. Messi M, Giacchetto I, Nagata K, Lanzavecchia A, Natoli G, Sallusto F. Memory and flexibility of cytokine gene expression as separable properties of human $\mathrm{T}(\mathrm{H}) 1$ and $\mathrm{T}(\mathrm{H}) 2$ lymphocytes. Nat
Immunol. 2003;4(1):78-86.

62. Dobin A, et al. STAR: ultrafast universal RNA-seq aligner. Bioinformatics. 2013;29(1):15-21

63. Patro R, Duggal G, Love MI, Irizarry RA, Kingsford C. Salmon provides fast and bias-aware quantification of transcript expression. Nat Meth ods. 2017;14(4):417-419.

64. Love MI, Huber W, Anders S. Moderated estimation of fold change and dispersion for RNA-seq data with DESeq2. Genome Biol. 2014;15(12):550.

65. Wickham H. ggplot2: Elegant Graphics for Data Analysis. Springer Verlag; 2016.

66. R Core Team. R Project for Statistical Computing. https://www.r-project.org. Updated June 12, 2020. Accessed June 12, 2020.

67. Tuomela S, et al. Comparative analysis of human and mouse transcriptomes of Th17 cell priming. Oncotarget. 2016;7(12):13416-13428. 